\title{
Power Quality Analysis Using Bilinear Time-Frequency Distributions
}

\author{
Abdul Rahim Abdullah ${ }^{1}$ and Ahmad Zuri Sha'ameri² \\ ${ }^{1}$ Faculty of Electrical Engineering, Technical university of Malaysia Malacca, 76100 Malacca, Malaysia \\ ${ }^{2}$ Faculty of Electrical Engineering, Technical university of Malaysia, 81310 Johor, Malaysia
}

Correspondence should be addressed to Abdul Rahim Abdullah, abdulr@utem.edu.my

Received 8 January 2010; Revised 4 June 2010; Accepted 8 December 2010

Academic Editor: Ulrich Heute

Copyright (c) 2010 A. R. Abdullah and A. Z. Sha'ameri. This is an open access article distributed under the Creative Commons Attribution License, which permits unrestricted use, distribution, and reproduction in any medium, provided the original work is properly cited.

\begin{abstract}
Bilinear time-frequency distributions (TFDs) are powerful techniques that offer good time and frequency resolution of timefrequency representation (TFR). It is very appropriate to analyze power quality signals which consist of nonstationary and multifrequency components. However, the TFDs suffer from interference because of cross-terms. Many TFDs have been implemented, and there is no fixed window or kernel that can remove the cross-terms for all types of signals. In this paper, the bilinear TFDs are implemented to analyze power quality signals such as smooth-windowed Wigner-Ville distribution (SWWVD), Choi-Williams distribution (CWD), B-distribution (BD), and modified B-distribution (MBD). The power quality signals focused are swell, sag, interruption, harmonic, interharmonic, and transient based on IEEE Std, 1159-1995. A set of performance measures is defined and used to compare the TFRs. It shows that SWWVD presents the best performance and is selected for power quality signal analysis. Thus, an adaptive optimal kernel SWWVD is designed to determine the separable kernel automatically from the input signal.
\end{abstract}

\section{Introduction}

Power quality is an issue that is becoming increasingly important to electricity consumers at all levels of usage [1]. Poor power quality can cause very serious problems like reduction of lifetime of the load, the ineffective performance of protection devices, and instabilities and interruptions in manufacturing operation. For example, voltage sags to $80 \%$ of the nominal voltage with durations of $40 \mathrm{~ms}$ or greater would shut down the control electronics of production line of an industrial plant [2]. Thus, there is a need for heightened awareness of power quality among electricity users that require ultrahigh availability of service and precision manufacturing systems. Accordingly, an automated monitoring system is required to provide adequate coverage of the entire system, understand the causes of these disturbances, resolve existing problems, and predict future problems [1]. Prompt and accurate diagnosis of problems will ensure quality of power line signal, reduce diagnostic time in the presence of power disturbance, and rectify failures.
In the current research trend, short-time Fourier transform (STFT) [3] is a popular technique for power quality signals analysis. The technique presents the signals jointly in time-frequency representation (TFR) which provides temporal and spectral information. However, it has the limitation of a fixed window width that results is a compromise between time and frequency resolution. The greater temporal resolution required, the worse frequency resolution will be and vice versa. To overcome the limitation of the fixed resolution of STFT, wavelet transform (WT) was proposed by various researchers [4]. WT offers high time resolution for high frequency component and high frequency resolution for low frequency component. Consequently, the technique is suitable to detect the duration of high frequency signal such as transient. For low frequency signal, typically sag, swell, and interruption, it does not produce reliable results [5]. In addition, WT also exhibits some disadvantages such as its computation burden, sensitivity to noise level, and the dependency of its accuracy on the chosen basis wavelet [6]. 
Bilinear time-frequency distributions (TFDs) [7] have been intensively used to characterize and analyze nonstationary signals. The bilinear TFDs offer a good time and frequency resolution and are successfully applied to various real-life problems such as radar, sonar, seismic data analysis, biomedical engineering, and automatic emission. However, the TFDs suffer from the presence of crossterms interferences because of its bilinear structure. This inhibits interpretation of its TFR, especially when signal has multiple frequency components. Some members of the bilinear TFDs are Wigner-Ville distribution (WVD), windowed Wigner-Ville distribution (WWVD), smoothwindowed Wigner-Ville distribution (SWWVD), ChoiWilliams distribution (CWD), B-distribution (BD), modified B-distribution (MBD), and Born-Jordan distribution (BJD). An analysis of the autoterms presentation using the reduced interference distributions (RID) has been discussed in [8]. A procedure for designing a kernel that will produce the desired autoterm shape and an optimal kernel with respect to the autoterm quality and cross-term were demonstrated.

In this paper, bilinear TFDs are implemented to analyze power quality signals. The popular bilinear TFDs are chosen such as SWWVD, CWD, BD, and MBD. To verify the performance of the TFDs, a set of performance measures is defined to compare the TFRs in terms of main-lobe width (MLW), peak-to-side lobe ratio (PSLR), absolute percentage error (APE), and signal-to-cross-terms ratio (SCR). From the comparison, the best bilinear TFD is chosen, and its adaptive optimal kernel system is designed. The adaptive system is to determine the optimal kernel parameters, automatically from the input signal, without prior knowledge of the signal. The optimal kernel is capable of removing the cross-terms, preserving the autoterms, and maintaining accurate TFR.

\section{Power Quality Signal}

According to the IEEE Standards 1159, electromagnetic phenomena are classified into several groups as shown in Table 1 [9]. This paper focuses on six types of power quality signals: swell, sag, interruption, harmonic, interharmonic, and transient.

\section{Signal Model}

This paper divides the power quality signals into three classes. They are voltage variation for swell, sag, and interruption signal, waveform distortion for harmonic and interharmonic signal, and transient for transient signal. The signal models of the classes are formed as a complex exponential signal, and defined as

$$
\begin{gathered}
z_{\mathrm{vv}}(t)=e^{j 2 \pi f_{1} t} \sum_{k=1}^{3} A_{k} \Pi_{k}\left(t-t_{k-1}\right), \\
z_{\mathrm{wd}}(t)=e^{j 2 \pi f_{1} t}+A e^{j 2 \pi f_{2} t}
\end{gathered}
$$

$$
\begin{aligned}
& z_{\text {trans }}(t)= e^{j 2 \pi f_{1} t} \sum_{k=1}^{3} \Pi_{k}\left(t-t_{k-1}\right) \\
&+A e^{-1.25\left(t-t_{1}\right) /\left(t_{2}-t_{1}\right)} e^{j 2 \pi f_{2}\left(t-t_{1}\right)} \Pi_{2}\left(t-t_{1}\right), \\
& \Pi_{k}(t)= \begin{cases}1, & \text { for } 0 \leq t \leq t_{k}-t_{k-1}, \\
0, & \text { elsewhere }\end{cases}
\end{aligned}
$$

where $z_{\mathrm{vv}}(t), z_{\mathrm{wd}}(t)$, and $z_{\text {trans }}(t)$ are the voltage variation, waveform distortion, and transient signal, respectively. $k$ is the signal component sequence, $A_{k}$ is the signal component amplitude, $f_{1}$ and $f_{2}$ are the signal frequency, $t$ is the time, and $\Pi(t)$ is a box function of the signal. In this analysis, $f_{1}, t_{0}$, and $t_{3}$ are set at $50 \mathrm{~Hz}, 0 \mathrm{~ms}$, and $200 \mathrm{~ms}$, and other parameters are defined as follows:

(1) swell: $A_{1}=A_{3}=1, A_{2}=1.2, t_{1}=100 \mathrm{~ms}, t_{2}=$ $140 \mathrm{~ms}$,

(2) sag: $A_{1}=A_{3}=1, A_{2}=0.8, t_{1}=100 \mathrm{~ms}, t_{2}=140 \mathrm{~ms}$,

(3) interruption: $A_{1}=A_{3}=1, A_{2}=0, t_{1}=100 \mathrm{~ms}$, $t_{2}=140 \mathrm{~ms}$,

(4) harmonic: $A=0.25, f_{2}=250 \mathrm{~Hz}$,

(5) interharmonic: $A=0.25, f_{2}=275 \mathrm{~Hz}$,

(6) transient: $A=0.5, f_{2}=1000 \mathrm{~Hz}, t_{1}=100 \mathrm{~ms}, t_{2}=$ $115 \mathrm{~ms}$.

\section{Bilinear Time-Frequency Distribution}

Bilinear TFDs are powerful tools in the analysis of nonstationary and multicomponent signals. Many of these TFDs are invariant to time and frequency translations and can be considered as energy distribution in time-frequency domain [10]. From the TFR, characteristics of the signals can be calculated and used as input for signals classification. The signal characteristics are duration of swell, sag, interruption, and transient and average of total waveform distortion, total harmonic distortion, and total nonharmonic distortion. Further discussion of the signal characteristics can be found in [11].

In general, the bilinear TFDs can be formulated as

$$
P_{z}(t, f)=\int_{-\infty}^{\infty} G(t, \tau) \underset{(t)}{*} K_{z}(t, \tau) \exp (-j 2 \pi f \tau) d \tau,
$$

where $G(t, \tau)$ is the time-lag kernel function, $K_{z}(t, \tau)$ is the bilinear product, and the asterisk with $t$ denotes the time convolution of the signals. The bilinear product is further defined as

$$
K_{z}(t, \tau)=z\left(t+\frac{\tau}{2}\right) z^{*}\left(t-\frac{\tau}{2}\right),
$$

where $z(t)$ is the analytic signal of interest. Smoothwindowed Wigner-Ville distribution (SWWVD) has a separable kernel [12] which is capable of reducing the effects of the interferences or cross-terms and at the same time, having 
TABLE 1: Categories and typical characteristics of power system electromagnetic phenomena [9].

\begin{tabular}{|c|c|c|c|}
\hline Categories & Typical spectral content & Typical duration & Typical voltage magnitude \\
\hline \multicolumn{4}{|l|}{ 1.0 Transients } \\
\hline \multicolumn{4}{|l|}{ 1.1 Impulsive } \\
\hline 1.1.1 Nanosecond & $5 \mathrm{~ns}$ rise & $<50 \mathrm{~ns}$ & \\
\hline 1.1.2 Microsecond & $1 \mu$ s rise & $50 \mathrm{~ns}-1 \mathrm{~ms}$ & \\
\hline 1.1.3 Millisecond & $0.1 \mathrm{~ms}$ rise & $>1 \mathrm{~ms}$ & \\
\hline \multicolumn{4}{|l|}{1.2 Oscillatory } \\
\hline 1.2.1 Low frequency & $<5 \mathrm{kHz}$ & $0.3-50 \mathrm{~ms}$ & $0-4 \mathrm{pu}$ \\
\hline 1.2.2 Medium frequency & $5-500 \mathrm{kHz}$ & $20 \mathrm{~ms}$ & $0-8 \mathrm{pu}$ \\
\hline 1.2.3 High frequency & $0.5-5 \mathrm{MHz}$ & $5 \mathrm{~ms}$ & $0-4 \mathrm{pu}$ \\
\hline \multicolumn{4}{|l|}{ 2.0 Short duration variations } \\
\hline \multicolumn{4}{|l|}{2.1 Instantaneous } \\
\hline 2.1.1 Sag & & $0.5-30$ cycles & $0.1-0.9 \mathrm{pu}$ \\
\hline 2.1.2 Swell & & $0.5-30$ cycles & $1.1-1.8 \mathrm{pu}$ \\
\hline \multicolumn{4}{|l|}{ 2.2 Momentary } \\
\hline 2.2.1 Interruption & & 0.5 cycles $-3 \mathrm{~s}$ & $<0.1 \mathrm{pu}$ \\
\hline 2.2.2 Sag & & 30 cycles $-3 \mathrm{~s}$ & $0.1-0.9 \mathrm{pu}$ \\
\hline 2.2.3 Swell & & 30 cycles $-3 \mathrm{~s}$ & $1.1-1.4 \mathrm{pu}$ \\
\hline \multicolumn{4}{|l|}{ 2.3 Temporary } \\
\hline 2.3.1 Interruption & & $3 \mathrm{~s}-1 \mathrm{~min}$ & $<0.1 \mathrm{pu}$ \\
\hline 2.3.2 Sag & & $3 \mathrm{~s}-1 \mathrm{~min}$ & $0.1-0.9 \mathrm{pu}$ \\
\hline 2.3.3 Swell & & $3 s-1 \min$ & $1.1-1.2 \mathrm{pu}$ \\
\hline \multicolumn{4}{|l|}{ 3.0 Long duration variations } \\
\hline 3.1 Interruption, sustained & & $>1 \mathrm{~min}$ & $0.0 \mathrm{pu}$ \\
\hline 3.2 Undervoltages & & $>1 \mathrm{~min}$ & $0.8-0.9 \mathrm{pu}$ \\
\hline 3.3 Overvoltages & & $>1 \mathrm{~min}$ & $1.1-1.2 \mathrm{pu}$ \\
\hline 4.0 Voltage imbalance & & steady state & $0.5-2 \%$ \\
\hline \multicolumn{4}{|l|}{ 5.0 Waveform distortion } \\
\hline 5.1 DC offset & & Steady state & $0-0.1 \%$ \\
\hline 5.2 Harmonics & $0-100$ th $\mathrm{H}$ & Steady state & $0-20 \%$ \\
\hline 5.3 Interharmonics & $0-6 \mathrm{kHz}$ & Steady state & $0-2 \%$ \\
\hline 5.4 Notching & & Steady state & \\
\hline 5.5 Noise & Broad band & Steady state & $0-1 \%$ \\
\hline 6.0 Voltage fluctuations & $<25 \mathrm{~Hz}$ & Intermittent & $0.1-7 \%$ \\
\hline 7.0 Power frequency variations & & $<10 s$ & \\
\hline
\end{tabular}

a high time-frequency resolution. The general expression of the separable kernel is written as

$$
G(t, \tau)=H(t) w(\tau)
$$

where $H(t)$ is the time smooth (TS) function, $w(\tau)$ is the lag window function, and its corresponding TFD can be expressed as

$$
\rho_{z, \text { swwvd }}(t, f)=\int_{-\infty}^{\infty} H(t) \underset{(t)}{*} K_{z}(t, \tau) w(\tau) e^{-j 2 \pi f \tau} d \tau
$$

In this paper, Hamming window is used as the lag window and raised-cosine pulse as the TS function. The hamming window and the raised-cosine pulse [12] are defined as

$$
w(\tau)= \begin{cases}0.54+0.46 \cos \left(\frac{\pi \tau}{T_{g}}\right), & \text { for }-T_{g} \leq \tau \leq T_{g}, \\ 0, & \text { elsewhere }\end{cases}
$$

$$
H(t)= \begin{cases}1+\cos \left(\frac{\pi t}{T_{\mathrm{sm}}}\right), & \text { for } 0 \leq t \leq T_{\mathrm{sm}} \\ 0, & \text { elsewhere }\end{cases}
$$


The lag window, $w(\tau)$, has a cutoff lag at $\tau=T_{g}$. The Doppler representation of the TS function, $H(t)$, that is obtained from the Fourier transform with respect to time is

$$
\begin{aligned}
h(v)= & \frac{\sin \left(\pi v T_{\mathrm{sm}}\right)}{\pi v T_{\mathrm{sm}}}+\frac{1}{2} \frac{\sin \left(\pi\left(v-1 / 2 T_{\mathrm{sm}}\right)\right)}{\pi\left(v-1 / 2 T_{\mathrm{sm}}\right)} \\
& +\frac{1}{2} \frac{\sin \left(\pi\left(v+1 / 2 T_{\mathrm{sm}}\right)\right)}{\pi\left(v+1 / 2 T_{\mathrm{sm}}\right)},
\end{aligned}
$$

where it is a low-pass filter in the Doppler domain, and the cutoff Doppler frequency is

$$
v_{c}=\frac{3}{2 T_{\mathrm{sm}}} \text {. }
$$

The Choi-Williams distribution (CWD) kernel is developed to reduce interference in TFDs [7] and can be defined as

$$
G(t, \tau)=\frac{\sqrt{\pi \sigma}}{|\tau|} e^{-\pi^{2} \sigma t^{2} / \tau^{2}},
$$

where $\sigma$ is a real parameter that can control the resolution and the cross-terms reduction [10]. This kernel has shown good performance in reducing cross-terms while keeping high resolution with a compromise between these two requirements.

The B-distribution (BD) kernel [10] is defined in the time-lag plane and can be expressed as

$$
G(t, \tau)=|\tau|^{\beta} \cosh ^{-2 \beta} t,
$$

where $\beta$ is a positive real parameter that controls the degree of smoothing, and its value is between zero and unity. This kernel is a low-pass filter in the Doppler domain but not in the lag domain.

To improve the time resolution, the B-distribution was modified by making the lag-dependent factor exactly constant [10]. The resulting modified B-distribution (MBD) had a lag-independent kernel and can be defined as

$$
G(t, \tau)=\frac{\cosh ^{-2 \beta} t}{\int_{-\infty}^{\infty} \cosh ^{-2 \beta} \xi d \xi} .
$$

\section{Time-Lag Signal Characteristic}

Generally, bilinear product of the signal interest is represented in time-lag representation. The bilinear product consists of autoterms and cross-terms and can be defined as

$$
K_{z}(t, \tau)=K_{z \text {,auto }}(t, \tau)+K_{z, \text { cross }}(t, \tau) .
$$

In the time-lag representation, normally, the autoterms are concentrated along the time axis and centered at $\tau=$ 0 , while the cross-terms are located away from the axis. The autoterms must be preserved, while the cross-terms are suppressed by choosing appropriate kernel parameters. For SWWVD, TS function is used to remove Doppler frequency component existing in cross-terms, while lag window suppresses cross-terms that lie away from the origin of the lag axis. Detail derivation of the autoterms and crossterms for all signals that are shown in (17) to (32) is derived in Appendix A.

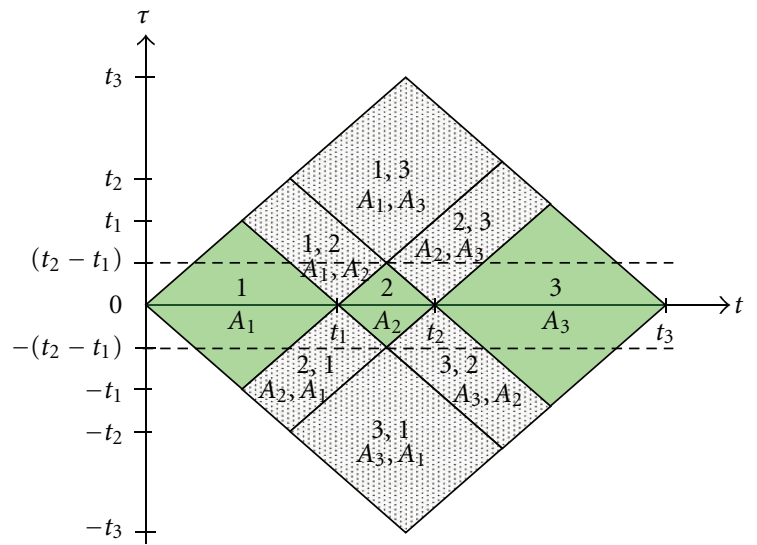

Figure 1: Bilinear product of the voltage variation signal. The autoterms are highlighted in green, while the cross-terms are densely dotted.

5.1. Bilinear Product of Voltage Variation Signal. Voltage variation signal in (1) has a variation in the root mean square (RMS) value from nominal voltage [9]. The autoterms and cross-terms of this signal can be expressed as

$$
\begin{gathered}
K_{\text {auto,vv }}(t, \tau)=\sum_{k=1}^{3} A_{k}^{2} e^{j 2 \pi f_{1} \tau} K_{\Pi_{k, k}}(t, \tau), \\
K_{\text {cross,vv }}(t, \tau)=\sum_{k=1}^{3} \sum_{\substack{l=1 \\
k \neq l}}^{3} A_{k} A_{l} e^{j 2 \pi f_{1} \tau} K_{\Pi_{k, l}}(t, \tau),
\end{gathered}
$$

where $k$ and $l$ represent the signal component sequence, $A_{k}$ and $A_{l}$ are the signal components amplitude, and the bilinear product of the box function, $\Pi(t)$, is defined as

$$
K_{\Pi_{k, l}}(t, \tau)=\Pi_{k}\left(t+\frac{\tau}{2}-t_{k}\right) \Pi_{l}\left(t-\frac{\tau}{2}-t_{l}\right) .
$$

From (17), it is observed that the autoterms lie along the time axis and are centered at $\tau=0$, while the cross-terms are elsewhere as shown in Figure 1.

For example, autoterm when $k=1$ and $l=1$ is expressed as

$$
K_{\text {auto,vv }}\left(t-\frac{t_{1}}{2}, \tau\right)=A_{1}^{2} e^{j 2 \pi f_{1} \tau} K_{\Pi_{1,1}}\left(t-\frac{t_{1}}{2}, \tau\right) .
$$

This autoterm is located at $t=t_{1} / 2$ and is centered at the origin of the lag axis. It has a single lag-frequency component which is at $f=f_{1}$. Similar result is observed for autoterm when $k=2$ and $l=2$. This autoterm which is at $t=$ $t_{1} / 2$ is also centered at the origin of the lag axis and has a single lag-frequency component at $f=f_{1}$. It can be defined as

$$
K_{\text {auto,vv }}\left(t-\frac{t_{1}+t_{2}}{2}, \tau\right)=A_{2}^{2} e^{j 2 \pi f_{1} \tau} K_{\Pi_{2,2}}\left(t-\frac{t_{1}+t_{2}}{2}, \tau\right) .
$$


Meanwhile, for cross-term when $k=1$ and $l=2$, it is located at $t=\left(t_{2}+2 t_{1}\right) / 4$ and $\tau=t_{2} / 2$. The cross-term is due to the interaction between 1st and 2 nd signal component and has only a single lag-frequency component at $f=f_{1}$. It can be expressed as

$$
\begin{aligned}
K_{\text {cross, }, v} & \left(t-\frac{t_{2}+2 t_{1}}{4}, \tau-\frac{t_{2}}{2}\right) \\
= & A_{1} A_{2} e^{j 2 \pi f_{1} \tau} K_{\Pi_{1,2}}\left(t-\frac{t_{2}+2 t_{1}}{4}, \tau-\frac{t_{2}}{2}\right) .
\end{aligned}
$$

Another example is cross-term which is due to the interaction between 2nd and 1st signal component. This cross-term is centered at $t=\left(t_{2}+2 t_{1}\right) / 4$ and $\tau=t_{2} / 2$ and also has only a single lag-frequency component at $f=f_{1}$ as expressed in the following equation:

$$
\begin{aligned}
K_{\text {cross, vv }} & \left(t-\frac{t_{2}+2 t_{1}}{4}, \tau+\frac{t_{2}}{2}\right) \\
= & A_{1} A_{2} e^{j 2 \pi f_{1} \tau} K_{\Pi_{1,2}}\left(t-\frac{t_{2}+2 t_{1}}{4}, \tau+\frac{t_{2}}{2}\right) .
\end{aligned}
$$

The examples above prove that the autoterms are centered at $\tau=0$ and lie along the time axis, while the crossterms are elsewhere. Since the signal has only frequency component at $f=f_{1}$, it results that the autoterms and cross-terms have a lag-frequency component at $f=f_{1}$ and zero Doppler frequency. Thus, in order to suppress the cross-terms and to preserve the autoterms, lag window should cover all autoterms while removing the cross-terms as much as possible. The lag window width, $T_{g}$, can be set as

$$
\left|T_{g}\right| \leq t_{2}-t_{1}
$$

By using this limit, cross-terms such as when $k=1, l=2$ and $k=2, l=3$ are preserved, since they are adjacent to the autoterms as shown in Figure 1. The remaining cross-terms can be reduced by using smaller $T_{g}$, but it will compromise the concentration of the autoterms. This results in smearing in frequency domain that reduces frequency resolution. In addition, the lag window width should contain at least one cycle of fundamental signal such that $T_{g} \geq 1 / 2 f_{1}$. The actual effect of this setting will be discussed in the next section.

Since the cross-terms do not have Doppler frequency, the use of the TS function will not contribute to the cross-terms suppression. Thus, the resulting TFD that uses a lag window and an impulse function as TS function is also known as windowed Wigner-Ville distribution (WWVD). It can be expressed as

$$
\rho_{z, \mathrm{wwvd}}(t, f)=\int_{-\infty}^{\infty} K_{z}(t, \tau) w(\tau) e^{-j 2 \pi f \tau} d \tau,
$$

where $w(\tau)$ is the lag window.

5.2. Bilinear Product of Waveform Distortion Signal. Waveform distortion signal is a steady-state signal which consists of multiple frequency components [13]. The autoterm and cross-term of the signal in (2) can be defined as

$$
K_{\text {auto }, z w d}(t, \tau)=e^{j 2 \pi f_{1} \tau}+A^{2} e^{j 2 \pi f_{2} \tau},
$$

$$
K_{\text {cross }, z w d}(t, \tau)=2 A e^{j 2 \pi\left(\left(f_{2}+f_{1}\right) / 2\right) \tau} \cos \left(2 \pi\left(f_{2}-f_{1}\right) t\right) .
$$

As shown in (25), the autoterm is centered at the origin of the lag axis and has two lag-frequency components which are $f_{1}$ and $f_{2}$. For the cross-term as shown in (26), it is also centered at the origin of the lag axis. However, the cross-term consists of a lag-frequency component at $f=\left(f_{2}+f_{1}\right) / 2$ and a Doppler frequency component at $v=\left(f_{2}-f_{1}\right)$.

Based on the observation, the Doppler frequency component only exists in the cross-term. TS function which is a low-pass filter in Doppler frequency domain can be used to remove the cross-term. Since the Doppler frequency component is at $v=\left(f_{2}-f_{1}\right)$, the Doppler cutoff frequency should be set at $v_{c} \leq\left|f_{2}-f_{1}\right|$. It can be achieved by setting the TS function parameter, $T_{\mathrm{sm}}$, as

$$
T_{\mathrm{sm}} \geq \frac{3}{2\left|f_{2}-f_{1}\right|} .
$$

For signal that has more than two frequency components, $\left|f_{2}-f_{1}\right|$ is set as the smallest frequency deviation among the signal frequency components. When $T_{\mathrm{sm}}$ is set lower than the limit in (27), the cutoff frequency will be $v_{c}>\left|f_{2}-f_{1}\right|$ that will include the cross-term. Thus, the TS function will not be able to remove the cross-term. Besides that, any higher $T_{\mathrm{sm}}$ value would result in a small cutoff Doppler frequency but would cause the autoterm to smear in time. Thus, $T_{\mathrm{sm}}$ should be set at an appropriate value to remove the cross-term and avoid the smearing of autoterm in time.

Besides using the TS function to remove the crossterms, lag window is also used to obtain desirable lagfrequency resolution in TFR. The lag-frequency resolution is set such that $\Delta f \leq f_{1} / 2$ to differentiate harmonic and interharmonic frequency components. Therefore, the lag window width should be set at $T_{g} \geq 1 / 2 \Delta f$. Higher $T_{g}$ offers higher lag-frequency resolution, but it increases computation complexity and memory size to calculate TFR. Thus, $T_{g}$ should be set at a sufficient value to obtain desirable lag-frequency resolution and avoid higher computation complexity and memory size used. In this analysis, since the signal fundamental frequency chosen is at $f_{1}=50 \mathrm{~Hz}$, $T_{g}$ is set at minimum value which is $20 \mathrm{~ms}$ to reduce the computation complexity and memory size of the analysis. It results in the fact that the lag-frequency resolution of the TFR is $\Delta f=25 \mathrm{~Hz}$. In addition, the setting is also applicable for all waveform distortion signals.

5.3. Bilinear Product of Transient Signal. Transient signal is a sudden signal which changes in steady-state condition at nonfundamental frequency [9]. As indicated in transient signal model in (3), there are three signal components. The first and third components consist of fundamental signal, 
$f_{1}$, while the second component has additional frequency component which is transient frequency, $f_{2}$. Thus, the bilinear product of this signal produces three autoterms and seven cross-terms in time-lag representation as shown in Figure 2. The autoterms and cross-terms can be expressed as

$$
\begin{aligned}
K_{\text {auto,trans }}(t, \tau)= & e^{j 2 \pi f_{1} \tau} K_{\Pi_{1,1}}(t, \tau) \\
+ & \left(e^{j 2 \pi f_{1} \tau}+A^{2} e^{-2.5\left(t-t_{1}\right)} e^{j 2 \pi f_{2} \tau}\right) K_{\Pi_{2,2}}(t, \tau) \\
+ & e^{j 2 \pi f_{1} \tau} K_{\Pi_{3,3}}(t, \tau), \\
K_{\text {trans,cross }}(t, \tau)= & \sum_{k=1}^{3} \sum_{l=1}^{3} e^{j 2 \pi f_{1} \tau} K_{\Pi_{k, l}}(t, \tau) \\
& +\sum_{l=1}^{3} A e^{-1.25\left(t+\tau / 2-t_{1}\right)} e^{j 2 \pi\left(f_{2}-f_{1}\right) t-f_{2} t_{1}} \\
& \times e^{j 2 \pi\left(f_{2}+f_{1}\right) \tau / 2} K_{\Pi_{2, l}}(t, \tau) \\
& +\sum_{k=1}^{3} A e^{-1.25\left(t+\tau / 2-t_{1}\right)} e^{-j 2 \pi\left(f_{2}-f_{1}\right) t-f_{2} t_{1}} \\
& \times e^{j 2 \pi\left(f_{2}+f_{1}\right) \tau / 2} K_{\Pi_{k, 2}}(t, \tau) .
\end{aligned}
$$

Similar to the voltage variation signal, the autoterms in (28) are centered at $\tau=0$ and lie along the time axis as colored in Figure 2. For example, autoterm at $k=1$ is located at $t=t_{1} / 2$ and the origin of the lag axis. It has a lag frequency at $f=f_{1}$ and can be defined as

$$
K_{\text {auto,trans }}\left(t-\frac{t_{1}}{2}, \tau\right)=e^{j 2 \pi f_{1} \tau} K_{\Pi_{1,1}}\left(t-\frac{t_{1}}{2}, \tau\right)
$$

The location of the cross-terms in (29) is densely dotted in Figure 2. The figure shows that cross-terms that are generated by different signal components $(k \neq l)$ are located away from the time axis, $\tau \neq 0$. As example, a cross-term defined in (31) is produced because of the interaction between the first and second signal components $(k=1$ and $l=2)$. It is centered at $t=\left(t_{2}+2 t_{1}\right) / 4$ and $\tau=t_{2} / 2$ and has a Doppler frequency component at $v=\left(f_{2}-f_{1}\right)$ and two lag-frequency components at $f=f_{1}$ and $f=\left(f_{2}+f_{1}\right) / 2$ :

$$
\begin{aligned}
& K_{\text {trans,cross }}\left(t-\frac{t_{2}+2 t_{1}}{4}, \tau-\frac{t_{2}}{2}\right) \\
& =\left(e^{j 2 \pi f_{1} \tau}+A e^{-1.25\left(t+\tau / 2-t_{1}\right)} e^{-j 2 \pi\left(f_{2}-f_{1}\right) t-f_{2} t_{1}} e^{j 2 \pi\left(f_{2}+f_{1}\right) \tau / 2}\right) \\
& \quad \times K_{\Pi_{1,2}}\left(t-\frac{t_{2}+2 t_{1}}{4}, \tau-\frac{t_{2}}{2}\right) .
\end{aligned}
$$

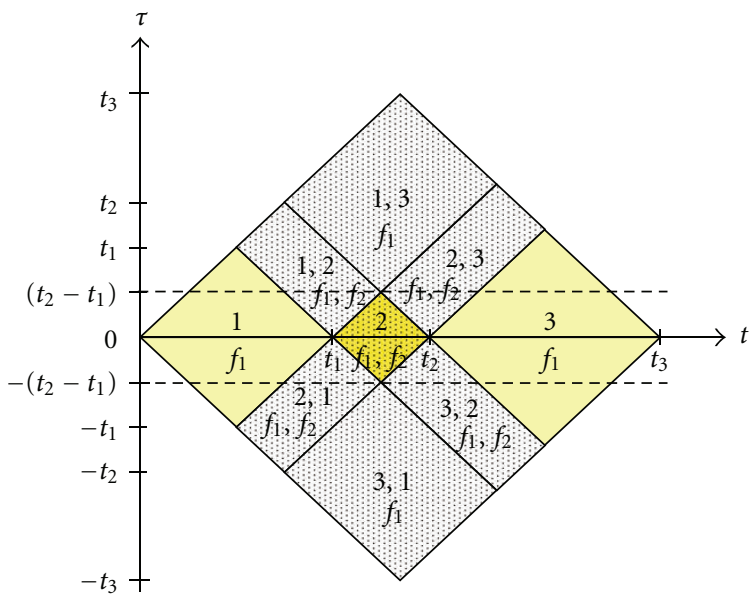

FIGURE 2: Bilinear product of the transient signal.

The second signal component has two different frequencies which are $f_{1}$ and $f_{2}$. Its bilinear product can be defined as

$$
\begin{aligned}
& K_{z_{2}}(t, \tau) \\
& =\left(e^{j 2 \pi f_{1} \tau}+A^{2} e^{-2.5\left(t-t_{1}\right)} e^{j 2 \pi f_{2} \tau}+2 A e^{-1.25\left(t+\tau / 2-t_{1}\right)}\right. \\
& \left.\quad \times \cos \left(j 2 \pi\left(f_{2}-f_{1}\right) t-f_{2} t_{1}\right) e^{j 2 \pi\left(f_{2}+f_{1}\right) \tau / 2}\right) K_{\Pi_{2,2}}(t, \tau) .
\end{aligned}
$$

This bilinear product introduces a cross-term which is located at $t=\left(t_{2}+t_{1}\right) / 2$ and also centered at $\tau=0$, where it is similar to the autoterms. The cross-term has a Doppler frequency component at $v=\left(f_{2}-f_{1}\right)$ and a lag frequency component at $f=\left(f_{2}+f_{1}\right) / 2$ and can be defined as

$$
\begin{aligned}
K_{\text {trans,cross }}\left(t-\frac{t_{2}+t_{1}}{2}, \tau\right) \\
=2 A e^{-1.25\left(t+\tau / 2-t_{1}\right)} e^{j 2 \pi\left(f_{2}+f_{1}\right) \tau / 2} \cos \left(j 2 \pi\left(f_{2}-f_{1}\right) t-f_{2} t_{1}\right) \\
\quad \times K_{\Pi_{2,2}}\left(t-\frac{t_{2}+t_{1}}{2}, \tau\right) .
\end{aligned}
$$

The purpose of using lag window in this signal is similar to the voltage variation signal. The lag window width is set such that $\left|T_{g}\right| \leq\left(t_{2}-t_{1}\right)$ to remove the cross-terms located away from the time axis and to preserve the autoterms lying along the time axis. In addition, similar to the waveform distortion signal, TS function is also employed to remove the Doppler frequency component of the remaining cross-terms. Since the Doppler frequency component is $v=\left(f_{2}-f_{1}\right)$, the cutoff Doppler frequency of the TS function is set at $v_{c} \leq\left|f_{2}-f_{1}\right|$ by setting the TS function parameter, $T_{\mathrm{sm}}$, as in (27). An appropriate value of $T_{\mathrm{sm}}$ and $T_{g}$ should be chosen to optimize the cross-terms suppression as well as to minimize the smearing of the autoterms in time and frequency domain. 
TABLE 2: Limit of the kernel parameters.

\begin{tabular}{lcc}
\hline Signal & $T_{g, \min }(\mathrm{ms})$ & $T_{\mathrm{sm}, \min }(\mathrm{ms})$ \\
\hline Swell & 10 & 0 \\
Sag & 10 & 0 \\
Interruption & 10 & 0 \\
Harmonic & 20 & 7.5 \\
Interharmonic & 20 & 6.67 \\
Transient & 10 & 1.578 \\
\hline
\end{tabular}

5.4. Kernel Parameters. The analysis of bilinear product in time-lag representation to determine kernel parameters for all power quality signals is discussed in the previous subsections. Based on the analysis, the limits of the kernel parameters as defined in (23) and (27) are summarized in Table 2. The smallest lag window width, $T_{g, \min }$, and TS function parameter, $T_{s m, \min }$, can be set in (9) and (10), respectively, to obtain sufficient cross-terms suppression with minimal autoterms bias as well as to reduce the computation complexity and memory size of the analysis.

\section{Performance Comparison of Kernel Parameters}

Several performance measures are created and used to verify the TFR of the bilinear TFDs. They are main-lobe width (MLW), peak-to-side lobe ratio (PSLR), signal-to-crossterms ratio (SCR), and absolute percentage error (APE). These measurements are adopted to evaluate concentration, accuracy, interference minimization, and resolution of TFRs [12].

6.1. Performance Measurements. MLW and PSLR are calculated from the power spectrum which is obtained from the frequency marginal of the TFR [12] as shown in Figure 3. MLW is the width at $3 \mathrm{~dB}$ below the peak of the power spectrum, while PSLR is the power ratio between the peak and the highest side lobe calculated in dB. Low MLW indicates good frequency resolution, and it gives the ability to resolve closely spaced sinusoids. PSLR should be as high as possible to resolve signal of various magnitudes.

SCR is a ratio of signal to cross-terms power in $\mathrm{dB}$. High SCR indicates high cross-terms suppression in the TFR and is defined as

$$
\mathrm{SCR}=10 \log \left(\frac{\text { signal power }}{\text { cross }- \text { terms power }}\right) .
$$

Besides the MLW, PSLR, and SCR, APE is also applied to quantify the accuracy of signal characteristics that are calculated from the TFR. This measurement has been discussed in [11] and is expressed as

$$
\mathrm{APE}=\frac{x_{i}-x_{m}}{x_{i}} \times 100 \%,
$$

where $x_{i}$ is actual value and $x_{m}$ is measured value. Low APE shows high accuracy of the measurement. In general,

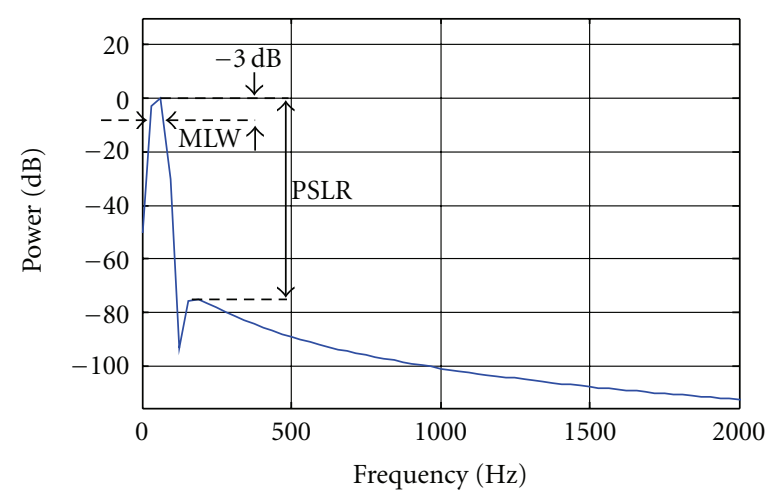

Figure 3: Performance measures used in the analysis.

an optimal kernel of TFD should have low MLW and APE while high PSLR and SCR.

6.2. Performance Comparison of Smooth-Windowed WignerVille Distribution. The performance of SWWVD with various kernel parameters for power quality signals is shown in Table 3. In this table, the kernel parameters are chosen based on the observation made in Section 5. The bold values in Table 3 presents the parameters that give optimal TFR for each type of signal. Even though, the discussion of the table will focus on transient signal and similar observation can be made for voltage variation and waveform distortion signal.

As shown in the table, the optimal kernel parameters for the transient signal are at $T_{g}=10 \mathrm{~ms}$ and $T_{\mathrm{sm}}=1.578 \mathrm{~ms}$. To observe the performance response corresponding to the kernel parameters, the performance measures of this signal at optimal $T_{\mathrm{sm}}$ with various $T_{g}$ and optimal $T_{g}$ with various $T_{\mathrm{sm}}$ are plotted in Figure 4. Figure 4(a) shows that, at optimal $T_{s m}$ and when $T_{g}$ is set higher, the MLW is smaller indicating a higher frequency resolution of the TFR. However, it suffers from the reduction of the cross-terms suppression which results in smaller SCR. This is because higher $T_{g}$ covers more adjacent cross-terms in lag axis in the bilinear product. As a result, the APE is higher which presents lower accuracy of the signal characteristic measurement. Since the fundamental frequency, $f_{1}$, is set at $50 \mathrm{~Hz}$, the minimum $T_{g}$ should be set at $10 \mathrm{~ms}$ to cover at least one cycle of the fundamental signal.

At the optimal $T_{g}$ and when $T_{\mathrm{sm}}$ is set higher than its optimal value, the SCR increases, while the MLW remains constant as shown in Figure 4(b). It indicates that higher $T_{\mathrm{sm}}$ improves the cross-terms suppression and does not give any effect to the frequency resolution. However, the APE is also higher which shows that the time resolution of the TFR is lower. This is because the application of TS function with higher $T_{\mathrm{sm}}$ increases the smearing of the autoterms in time domain. Thus, there is a compromise between cross-terms suppression and time resolution to obtain optimal TFR.

The optimal kernel parameters for voltage variation signal are at $T_{g}=10 \mathrm{~ms}$ and $T_{\mathrm{sm}}=0 \mathrm{~ms}$. For this signal, the use of the TS function does not introduce any improvement in the cross-terms suppression because all cross-terms have zero 


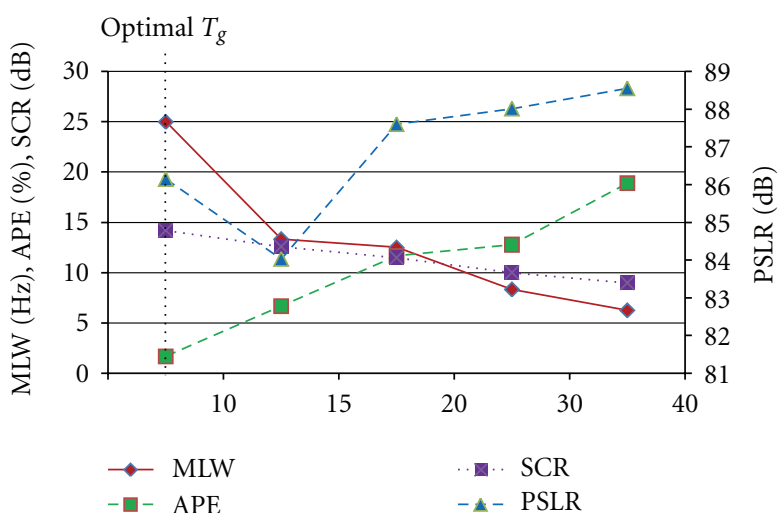

(a) MLW, APE, PSLR, and SCR at optimal $T_{\mathrm{sm}}$ with various $T_{g}$

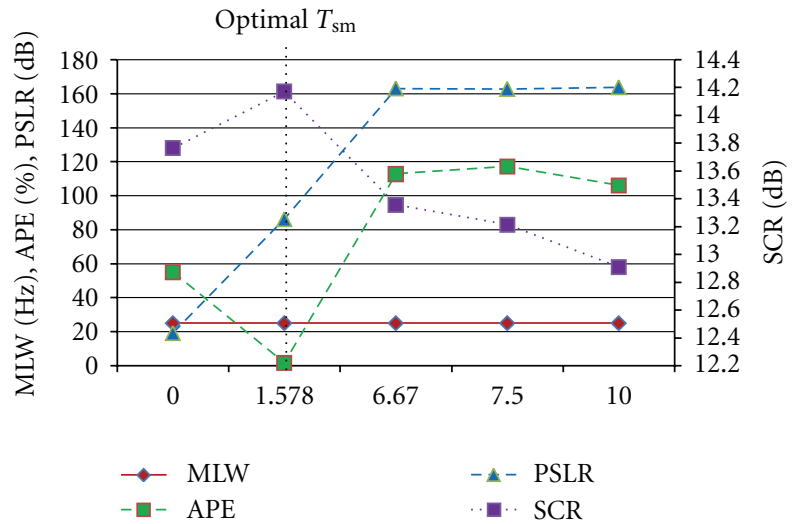

(b) MLW, APE, PSLR, and SCR at optimal $T_{g}$ with various $T_{\mathrm{sm}}$

FIgURE 4: Performance of the TFR using SWWVD with various kernel parameters for transient signal. (The kernel parameters chosen must give low MLW and APE but high PSLR and SCR.)

TABLE 3: Performance comparison of SWWVD with various kernel parameters.

\begin{tabular}{|c|c|c|c|c|c|c|c|}
\hline \multirow[t]{2}{*}{ Kernel Parameters } & \multirow{2}{*}{$\begin{array}{l}\text { Performance } \\
\text { measures }\end{array}$} & \multicolumn{6}{|c|}{ Signal } \\
\hline & & Swell & Sag & Interruption & Harmonic & Interharmonic & $\begin{array}{c}\text { Transient signal } \\
\text { Transient }\end{array}$ \\
\hline \multirow{4}{*}{$\begin{array}{l}T_{g}=10 \mathrm{~ms} \\
T_{\mathrm{sm}}=0 \mathrm{~ms}\end{array}$} & MLW $(\mathrm{Hz})$ & 25 & 25 & 25 & 25 & 25 & 25 \\
\hline & $\operatorname{PSLR}(\mathrm{dB})$ & 614.82 & 614.82 & 614.82 & 623.12 & 50.795 & 19.102 \\
\hline & $\mathrm{SCR}(\mathrm{dB})$ & 15.641 & 17.799 & 55.446 & 4.4785 & 4.5758 & 13.764 \\
\hline & $\operatorname{APE}(\%)$ & 0.2083 & 0.625 & 0.625 & 0.3755 & 100 & 55 \\
\hline \multirow{4}{*}{$\begin{array}{l}T_{g}=40 \mathrm{~ms} \\
T_{\mathrm{sm}}=0 \mathrm{~ms}\end{array}$} & MLW (Hz) & 6.25 & 6.25 & 6.25 & 6.25 & 6.25 & 6.25 \\
\hline & $\operatorname{PSLR}(\mathrm{dB})$ & 117.60 & 117.55 & 89.657 & 644.84 & 652.71 & 86.259 \\
\hline & $\operatorname{SCR}(\mathrm{dB})$ & 8.9462 & 11.216 & 48.903 & 9.0262 & 9.0721 & 9.4476 \\
\hline & $\operatorname{APE}(\%)$ & 1.4583 & 1.875 & 1.0417 & 141.27 & 25.031 & 19.444 \\
\hline \multirow{4}{*}{$\begin{array}{l}T_{g}=10 \mathrm{~ms} \\
T_{\mathrm{sm}}=1.578 \mathrm{~ms}\end{array}$} & MLW $(\mathrm{Hz})$ & 25 & 25 & 25 & 25 & 25 & 25 \\
\hline & $\operatorname{PSLR}(\mathrm{dB})$ & 218.09 & 216.68 & 198.78 & 18.835 & 49.889 & 86.145 \\
\hline & $\mathrm{SCR}(\mathrm{dB})$ & 13.491 & 15.038 & 35.107 & 5.6064 & 5.7679 & 14.171 \\
\hline & $\operatorname{APE}(\%)$ & 3.125 & 12.708 & 100 & 55.544 & 100 & 1.6667 \\
\hline \multirow{4}{*}{$\begin{array}{l}T_{g}=15 \mathrm{~ms} \\
T_{\mathrm{sm}}=1.578 \mathrm{~ms}\end{array}$} & MLW (Hz) & 13.333 & 13.333 & 13.333 & 13.333 & 13.333 & 13.333 \\
\hline & $\operatorname{PSLR}(\mathrm{dB})$ & 130.99 & 130.68 & 127.89 & 17.623 & 17.712 & 84.025 \\
\hline & $\mathrm{SCR}(\mathrm{dB})$ & 11.751 & 13.297 & 33.514 & 10.959 & 11.289 & 12.567 \\
\hline & $\operatorname{APE}(\%)$ & 69.791 & 117.08 & 100 & 100 & 100 & 6.6667 \\
\hline \multirow{4}{*}{$\begin{array}{l}T_{g}=20 \mathrm{~ms} \\
T_{\mathrm{sm}}=6.67 \mathrm{~ms}\end{array}$} & MLW (Hz) & 12.5 & 12.5 & 12.5 & 12.5 & 12.5 & 12.5 \\
\hline & PSLR (dB) & 229.98 & 228.53 & 210.04 & 51.168 & 638.24 & 154.53 \\
\hline & $\operatorname{SCR}(\mathrm{dB})$ & 9.8581 & 11.485 & 31.371 & 27.934 & 23.752 & 10.442 \\
\hline & APE (\%) & 14.583 & 29.375 & 100 & 20.142 & 0.125 & 107.78 \\
\hline \multirow{4}{*}{$\begin{array}{l}T_{g}=40 \mathrm{~ms} \\
T_{\mathrm{sm}}=6.67 \mathrm{~ms}\end{array}$} & MLW (Hz) & 6.25 & 6.25 & 6.25 & 6.25 & 6.25 & 6.25 \\
\hline & PSLR (dB) & 120.03 & 100.92 & 81.315 & 51.168 & 655.78 & 129.74 \\
\hline & $\operatorname{SCR}(\mathrm{dB})$ & 6.7221 & 8.4121 & 28.701 & 28.570 & 24.256 & 7.7198 \\
\hline & APE (\%) & 20.416 & 35.417 & 100 & 20.142 & 0.125 & 90.556 \\
\hline \multirow{4}{*}{$\begin{array}{l}T_{g}=20 \mathrm{~ms} \\
T_{\mathrm{sm}}=7.5 \mathrm{~ms}\end{array}$} & MLW $(\mathrm{Hz})$ & 12.5 & 12.5 & 12.5 & 12.5 & 12.5 & 12.5 \\
\hline & PSLR (dB) & 229.97 & 228.53 & 209.88 & 643.28 & 68.843 & 156.11 \\
\hline & $\operatorname{SCR}(\mathrm{dB})$ & 9.8073 & 11.439 & 31.289 & 41.007 & 31.001 & 10.248 \\
\hline & $\operatorname{APE}(\%)$ & 16.666 & 31.667 & 100 & 0.125 & 1.4268 & 115 \\
\hline \multirow{4}{*}{$\begin{array}{l}T_{g}=40 \mathrm{~ms} \\
T_{\mathrm{sm}}=7.5 \mathrm{~ms}\end{array}$} & MLW $(\mathrm{Hz})$ & 6.25 & 6.25 & 6.25 & 6.25 & 6.25 & 6.25 \\
\hline & PSLR (dB) & 122.91 & 102.56 & 111.22 & 664.29 & 651.32 & 131.79 \\
\hline & $\mathrm{SCR}(\mathrm{dB})$ & 6.6568 & 8.3551 & 28.600 & 41.739 & 32.356 & 7.4996 \\
\hline & $\operatorname{APE}(\%)$ & 21.458 & 36.667 & 100 & 0.125 & 0.125 & 97.778 \\
\hline
\end{tabular}


TABle 4: Performance comparison of Choi-Williams distribution.

\begin{tabular}{|c|c|c|c|c|c|c|c|}
\hline \multirow{3}{*}{ Kernel Parameters } & \multirow{3}{*}{$\begin{array}{l}\text { Performance } \\
\text { measures }\end{array}$} & \multicolumn{6}{|c|}{ Signal } \\
\hline & & \multicolumn{3}{|c|}{ Voltage variation signal } & \multicolumn{2}{|c|}{ Waveform distortion signal } & \multirow{2}{*}{$\begin{array}{c}\text { Transient signal } \\
\text { Transient }\end{array}$} \\
\hline & & Swell & Sag & Interruption & Harmonic & Interharmonic & \\
\hline \multirow{4}{*}{$\sigma=1.0$} & MLW $(\mathrm{Hz})$ & 2.34375 & 2.34375 & 2.34375 & 2.34375 & 2.34375 & 2.34375 \\
\hline & $\operatorname{PSLR}(\mathrm{dB})$ & 66.6589 & 66.6589 & 66.6589 & 45.5389 & 47.4593 & 67.5132 \\
\hline & $\mathrm{SCR}(\mathrm{dB})$ & 5.61185 & 7.81444 & 28.6804 & 21.4932 & 22.3112 & 7.0376 \\
\hline & $\operatorname{APE}(\%)$ & 2.70833 & 3.54166 & 81.8750 & 59.5457 & 59.0395 & 21.6667 \\
\hline \multirow{4}{*}{$\sigma=0.5$} & MLW $(\mathrm{Hz})$ & 2.34375 & 2.34375 & 2.34375 & 2.34375 & 2.34375 & 2.34375 \\
\hline & $\operatorname{PSLR}(\mathrm{dB})$ & 78.8655 & 78.8655 & 78.8655 & 45.1447 & 47.3009 & 81.7881 \\
\hline & $\mathrm{SCR}(\mathrm{dB})$ & 5.51383 & 7.68141 & 27.6884 & 22.9633 & 23.9232 & 6.75077 \\
\hline & $\operatorname{APE}(\%)$ & 1.45833 & 2.29166 & 85.2083 & 53.8937 & 55.8645 & 34.4444 \\
\hline \multirow{4}{*}{$\sigma=0.1$} & $\operatorname{MLW}(\mathrm{Hz})$ & 2.34375 & 2.34375 & 2.34375 & 2.34375 & 2.34375 & 2.34375 \\
\hline & $\operatorname{PSLR}(\mathrm{dB})$ & 51.309 & 51.309 & 51.309 & 45.3051 & 52.875 & 51.9201 \\
\hline & SCR (dB) & 6.0203 & 8.1977 & 27.1346 & 25.3153 & 26.4656 & 6.22225 \\
\hline & $\operatorname{APE}(\%)$ & 0.20833 & 0.62500 & 63.7500 & 49.3376 & 49.6516 & 49.4444 \\
\hline \multirow{4}{*}{$\sigma=0.05$} & MLW $(\mathrm{Hz})$ & 2.34375 & 2.34375 & 2.34375 & 2.34375 & 2.34375 & 2.34375 \\
\hline & PSLR (dB) & 52.0779 & 52.0779 & 52.0779 & 47.666 & 49.1118 & 53.6057 \\
\hline & $\mathrm{SCR}(\mathrm{dB})$ & 6.53223 & 8.73298 & 27.4525 & 26.7083 & 27.7299 & 6.30179 \\
\hline & APE (\%) & 0.20833 & 0.20833 & 56.8750 & 44.1498 & 43.7457 & 52.2222 \\
\hline \multirow{4}{*}{$\sigma=0.01$} & MLW $(\mathrm{Hz})$ & 5.85938 & 5.85938 & 5.85938 & 4.6875 & 4.6875 & 4.6875 \\
\hline & PSLR (dB) & 57.8314 & 57.8314 & 57.8314 & 59.4144 & 61.5886 & 67.2973 \\
\hline & $\mathrm{SCR}(\mathrm{dB})$ & 8.18709 & 10.4501 & 28.9207 & 30.6248 & 31.5286 & 7.20599 \\
\hline & APE (\%) & 0.62500 & 0.41666 & 75.0000 & 15.5563 & 28.2073 & 51.6667 \\
\hline \multirow{4}{*}{$\sigma=0.005$} & MLW $(\mathrm{Hz})$ & 5.85938 & 5.85938 & 5.85938 & 5.85938 & 5.85938 & 5.85938 \\
\hline & PSLR (dB) & 45.6061 & 45.6061 & 45.6061 & 62.4682 & 54.3076 & 57.5039 \\
\hline & $\mathrm{SCR}(\mathrm{dB})$ & 9.03793 & 11.3288 & 29.758 & 30.8003 & 32.5905 & 7.8471 \\
\hline & APE (\%) & 1.04166 & 0.62500 & 78.3333 & 13.1708 & 24.7269 & 48.8889 \\
\hline \multirow{4}{*}{$\sigma=0.001$} & MLW $(\mathrm{Hz})$ & 9.375 & 9.375 & 9.375 & 9.375 & 9.375 & 9.375 \\
\hline & $\operatorname{PSLR}(\mathrm{dB})$ & 53.3157 & 53.3157 & 53.3157 & 60.5077 & 56.1806 & 58.7548 \\
\hline & $\operatorname{SCR}(\mathrm{dB})$ & 11.2395 & 13.5999 & 32.0283 & 29.0768 & 30.1635 & 9.93482 \\
\hline & APE (\%) & 1.45833 & 1.25000 & 83.3333 & 2.36060 & 12.7563 & 49.4444 \\
\hline
\end{tabular}

Doppler frequency. In addition, higher $T_{\mathrm{sm}}$ reduces the time resolution of the TFR. Therefore, as the $T_{\text {sm }}$ is set higher, the SCR is lower, and APE is higher. For waveform distortion signal, the optimal kernel parameters for harmonic signal are at $T_{g}=20 \mathrm{~ms}$ and $T_{\mathrm{sm}}=7.5 \mathrm{~ms}$ while for interharmonic signal are at $T_{g}=20 \mathrm{~ms}$ and $T_{\mathrm{sm}}=6.67 \mathrm{~ms}$. All crossterms of these signals have Doppler frequency and can be removed by using the TS function at the optimal $T_{s m}$. Higher $T_{g}$ does not improve the cross-terms suppression. However, it is still used to set the frequency resolution of the TFR that can differentiate between harmonic and interharmonic frequency components.

6.3. Performance Comparison of Choi-Williams Distribution. Performance of the CWD is also compared with various kernel parameters. The kernel parameter, $\sigma$, is set at 1.0 , $0.05,0.1,0.05,0.01,0.005$, and 0.001 as shown in Table 4 .
This table shows that the optimal parameter for voltage variation, waveform distortion, and transient signal is at $\sigma=$ $0.05,0.001$, and 1.0 , respectively.

All signals present similar performance response when $\sigma$ is set higher or smaller than their optimal value. As example, the performance measures of sagsignal using various $\sigma$ is shown graphically in Figure 5. The graph illustrates that, when $\sigma$ is set higher than its optimal kernel, the MLW and SCR are smaller. Higher $\sigma$ increases frequency resolution of the TFR, but it reduces cross-terms suppression. As a result, the APE is higher. As $\sigma$ is set smaller, the SCR is higher because smaller $\sigma$ removes more cross-terms. However, the frequency and time resolution get worse, resulting in higher MLW and APE. Thus, $\sigma$ should be chosen based on the signal parameters, and a compromise between time and frequency resolution and cross-terms suppression is required to obtain optimal TFR. 


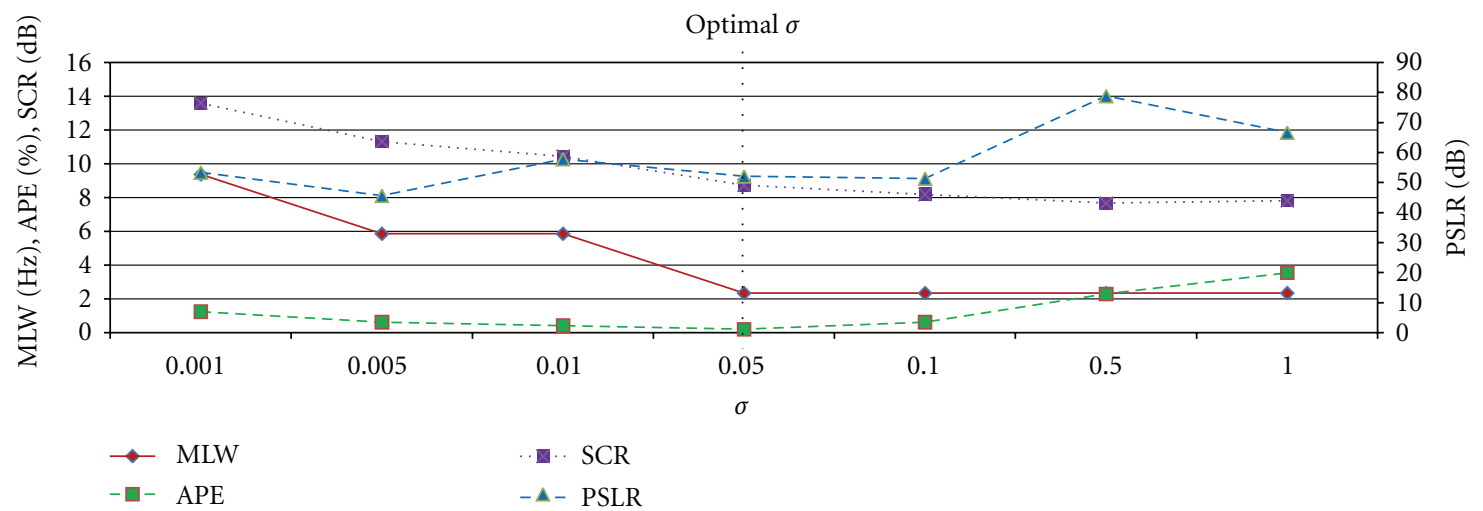

FIGURE 5: Performance comparison of the TFR using CWD with various $\sigma$ for sag signal.

Table 5: Performance comparison of B-distribution.

\begin{tabular}{|c|c|c|c|c|c|c|c|}
\hline \multirow{3}{*}{$\begin{array}{l}\text { Kernel } \\
\text { parameters }\end{array}$} & \multirow{3}{*}{$\begin{array}{c}\text { Performance } \\
\text { measures }\end{array}$} & \multicolumn{6}{|c|}{ Signal } \\
\hline & & \multicolumn{3}{|c|}{ Voltage variation signal } & \multicolumn{2}{|c|}{ Waveform distortion signal } & \multirow{2}{*}{$\begin{array}{c}\text { Transient } \\
\text { signal } \\
\text { Transient }\end{array}$} \\
\hline & & Swell & Sag & Interruption & Harmonic & Interharmonic & \\
\hline \multirow{4}{*}{$\beta=1.0$} & MLW $(\mathrm{Hz})$ & 2.34375 & 2.34375 & 2.34375 & 2.34375 & 2.34375 & 2.34375 \\
\hline & PSLR (dB) & 17.9819 & 17.9819 & 17.9819 & 17.8048 & 17.8037 & 17.9819 \\
\hline & $\mathrm{SCR}(\mathrm{dB})$ & 4.00059 & 6.18643 & 27.6292 & 17.8138 & 20.1651 & 6.25955 \\
\hline & $\operatorname{APE}(\%)$ & 26.4583 & 30.0000 & 100.000 & 23.5287 & 33.4150 & 100 \\
\hline \multirow{4}{*}{$\beta=0.5$} & MLW $(\mathrm{Hz})$ & 2.34375 & 2.34375 & 2.34375 & 2.34375 & 2.34375 & 2.34375 \\
\hline & PSLR (dB) & 20.4438 & 20.4438 & 20.4438 & 20.2938 & 20.2869 & 20.4438 \\
\hline & $\mathrm{SCR}(\mathrm{dB})$ & 4.22834 & 6.38194 & 26.697 & 20.8143 & 24.2531 & 6.3561 \\
\hline & $\operatorname{APE}(\%)$ & 9.37500 & 11.8750 & 100.000 & 16.9564 & 21.3484 & 100 \\
\hline \multirow{4}{*}{$\beta=0.1$} & MLW $(\mathrm{Hz})$ & 2.34375 & 2.34375 & 2.34375 & 2.34375 & 2.34375 & 2.34375 \\
\hline & PSLR (dB) & 41.6584 & 41.6584 & 41.6584 & 41.3606 & 41.2691 & 41.6584 \\
\hline & $\mathrm{SCR}(\mathrm{dB})$ & 4.75199 & 6.87431 & 26.1382 & 22.8579 & 24.2201 & 6.73587 \\
\hline & APE (\%) & 2.70833 & 3.75000 & 100.000 & 10.8960 & 12.3272 & 100 \\
\hline \multirow{4}{*}{$\beta=0.05$} & MLW $(\mathrm{Hz})$ & 2.34375 & 2.34375 & 2.34375 & 2.34375 & 2.34375 & 2.34375 \\
\hline & PSLR (dB) & 56.1906 & 56.1906 & 56.1906 & 55.0188 & 55 & 56.1906 \\
\hline & SCR (dB) & 4.88367 & 7.00392 & 26.1603 & 23.2079 & 24.1038 & 6.8444 \\
\hline & APE (\%) & 2.083333 & 3.12500 & 100.000 & 10.5308 & 10.1349 & 2.77778 \\
\hline \multirow{4}{*}{$\beta=0.01$} & MLW $(\mathrm{Hz})$ & 2.34375 & 2.34375 & 2.34375 & 2.34375 & 2.34375 & 2.34375 \\
\hline & PSLR (dB) & 82.4436 & 82.4436 & 82.4436 & 54.1945 & 63.1562 & 82.4436 \\
\hline & $\mathrm{SCR}(\mathrm{dB})$ & 5.0083 & 7.12755 & 26.205 & 19.9989 & 21.3782 & 6.94972 \\
\hline & APE $(\%)$ & 1.66666 & 2.50000 & 100.000 & 15.0836 & 10.2403 & 85.5556 \\
\hline \multirow{4}{*}{$\beta=0.005$} & MLW $(\mathrm{Hz})$ & 2.34375 & 2.34375 & 2.34375 & 2.34375 & 2.34375 & 2.34375 \\
\hline & PSLR (dB) & 100 & 100 & 100 & 54.0775 & 63.0764 & 100 \\
\hline & SCR (dB) & 5.04078 & 7.14442 & 26.2125 & 20.0266 & 21.1886 & 6.96154 \\
\hline & APE (\%) & 1.66666 & 2.5000 & 100.000 & 15.0483 & 10.2398 & 90 \\
\hline \multirow{4}{*}{$\beta=0.001$} & MLW (Hz) & 2.34375 & 2.34375 & 2.34375 & 2.34375 & 2.34375 & 2.34375 \\
\hline & PSLR (dB) & 100 & 100 & 100 & 53.9816 & 63.009 & 100 \\
\hline & $\mathrm{SCR}(\mathrm{dB})$ & 5.04217 & 7.15816 & 26.2188 & 20.0538 & 21.1648 & 6.9732 \\
\hline & APE $(\%)$ & 1.666667 & 2.50000 & 100.000 & 13.4147 & 10.2426 & 92.7778 \\
\hline
\end{tabular}

6.4. Performance Comparison of B-Distribution. $\mathrm{BD}$ is another TFD used in this paper. Table 5 presents the performance of the TFD with various kernel parameters, $\beta$, at $1.0,0.05,0.1,0.05,0.01,0.005$, and 0.001 . The result shows that the optimal kernel for voltage variation signal is at $\beta=0.001$ while waveform distortion and transient signal are at $\beta=0.05$. For all signals, as $\beta$ is set other than the optimal value, the MLW is similar, and the SCR is smaller. This indicates that $\beta$ does not change the frequency resolution and reduce the cross-terms suppression in the TFR. As a result, the APE is higher. The trends of this performance are shown in Figure 6 which proves that the optimal kernel of harmonic is at $\beta=0.05$.

6.5. Performance Comparison of Modified B-Distribution. MBD is also analyzed with various kernel parameters similar 


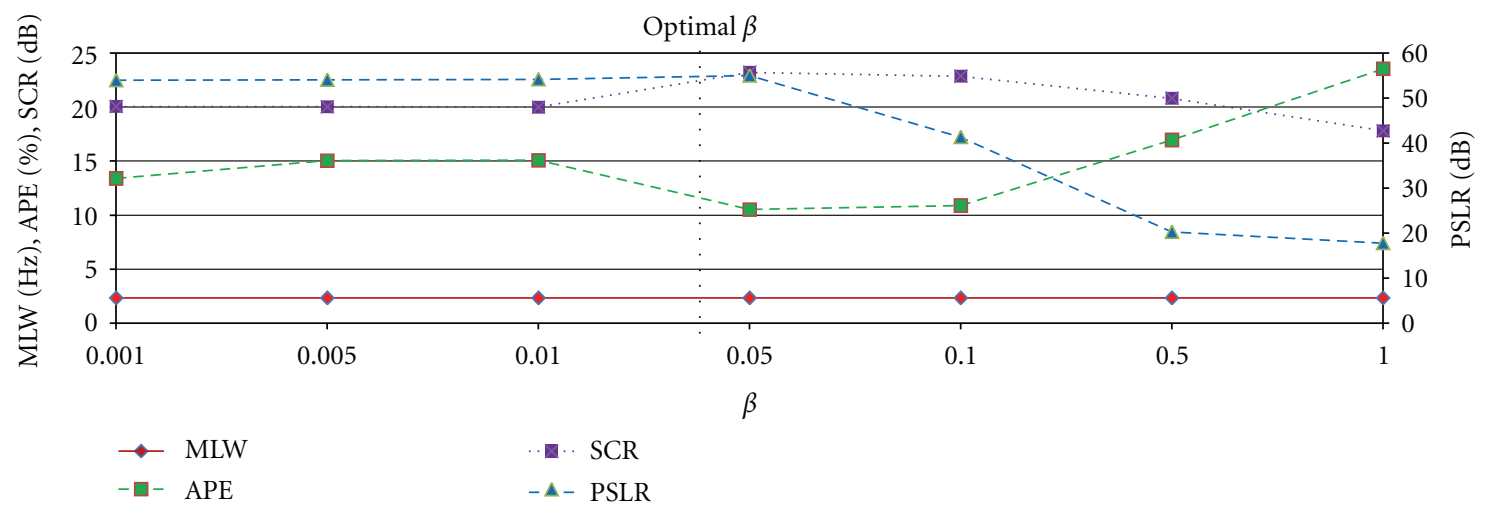

FIgURE 6: Performance comparison of the TFR using BD with various $\beta$ for harmonic signal.

TABLE 6: Performance comparison of modified B-distribution.

\begin{tabular}{|c|c|c|c|c|c|c|c|}
\hline \multirow[b]{3}{*}{$\begin{array}{l}\text { Kernel } \\
\text { parameters }\end{array}$} & \multirow[b]{3}{*}{$\begin{array}{c}\text { Performance } \\
\text { measures }\end{array}$} & \multicolumn{6}{|c|}{ Signal } \\
\hline & & \multicolumn{3}{|c|}{ Voltage variation signal } & \multicolumn{2}{|c|}{ Waveform distortion signal } & \multirow{2}{*}{$\begin{array}{c}\text { Transient } \\
\text { signal } \\
\text { Transient }\end{array}$} \\
\hline & & Swell & Sag & Interruption & Harmonic & Interharmonic & \\
\hline \multirow{4}{*}{$\beta=1.0$} & MLW (Hz) & 2.34375 & 2.34375 & 2.34375 & 2.34375 & 2.34375 & 2.34375 \\
\hline & PSLR (dB) & 100 & 100 & 100 & 45.1706 & 48.2892 & 100 \\
\hline & $\mathrm{SCR}(\mathrm{dB})$ & 5.60786 & 7.88928 & 29.1182 & 18.3383 & 19.6895 & 7.54363 \\
\hline & $\operatorname{APE}(\%)$ & 3.54166 & 4.79166 & 91.45833 & 12.7766 & 10.3902 & 100 \\
\hline \multirow{4}{*}{$\beta=0.5$} & MLW (Hz) & 2.34375 & 2.34375 & 2.34375 & 2.34375 & 2.34375 & 2.34375 \\
\hline & PSLR (dB) & 100 & 100 & 100 & 45.1608 & 48.2939 & 100 \\
\hline & $\mathrm{SCR}(\mathrm{dB})$ & 5.34929 & 7.57329 & 27.7477 & 19.2197 & 20.5864 & 7.31436 \\
\hline & $\operatorname{APE}(\%)$ & 3.12500 & 3.95833 & 96.87500 & 24.2547 & 31.7169 & 100 \\
\hline \multirow{4}{*}{$\beta=0.1$} & MLW (Hz) & 2.34375 & 2.34375 & 2.34375 & 2.34375 & 2.34375 & 2.34375 \\
\hline & PSLR (dB) & 100 & 100 & 100 & 55.1384 & 62.841 & 100 \\
\hline & $\mathrm{SCR}(\mathrm{dB})$ & 5.09544 & 7.23878 & 26.4945 & 19.8685 & 21.1567 & 7.04573 \\
\hline & APE (\%) & 2.08333 & 2.91666 & 100.0000 & 32.3782 & 43.5187 & 100 \\
\hline \multirow{4}{*}{$\beta=0.05$} & MLW (Hz) & 2.34375 & 2.34375 & 2.34375 & 2.34375 & 2.34375 & 2.34375 \\
\hline & PSLR (dB) & 100 & 100 & 100 & 54.5671 & 62.912 & 100 \\
\hline & $\mathrm{SCR}(\mathrm{dB})$ & 5.0679 & 7.19925 & 26.3538 & 20.0117 & 21.1938 & 7.01054 \\
\hline & APE (\%) & 1.66666 & 2.50000 & 100.0000 & 34.0133 & 44.4557 & 100 \\
\hline \multirow{4}{*}{$\beta=0.01$} & MLW (Hz) & 2.34375 & 2.34375 & 2.34375 & 2.34375 & 2.34375 & 2.34375 \\
\hline & PSLR (dB) & 100 & 100 & 100 & 54.0821 & 62.9751 & 100 \\
\hline & $\mathrm{SCR}(\mathrm{dB})$ & 5.04741 & 7.16898 & 26.2465 & 20.0253 & 21.1781 & 6.98279 \\
\hline & APE (\%) & 1.66666 & 2.50000 & 100.0000 & 34.2055 & 44.5223 & 100 \\
\hline \multirow{4}{*}{$\beta=0.005$} & MLW (Hz) & 2.34375 & 2.34375 & 2.34375 & 2.34375 & 2.34375 & 2.34375 \\
\hline & $\operatorname{PSLR}(\mathrm{dB})$ & 100 & 100 & 100 & 54.0199 & 62.9833 & 100 \\
\hline & $\mathrm{SCR}(\mathrm{dB})$ & 5.04496 & 7.16529 & 26.2334 & 20.0315 & 21.1759 & 6.97936 \\
\hline & APE (\%) & 1.66666 & 2.50000 & 100.0000 & 34.2260 & 44.5324 & 100 \\
\hline \multirow{4}{*}{$\beta=0.001$} & MLW (Hz) & 2.34375 & 2.34375 & 2.34375 & 2.34375 & 2.34375 & 2.34375 \\
\hline & PSLR (dB) & 100 & 100 & 100 & 53.9698 & 62.99 & 100 \\
\hline & $\mathrm{SCR}(\mathrm{dB})$ & 5.04301 & 7.16236 & 26.223 & 20.0293 & 21.1739 & 6.97661 \\
\hline & APE $(\%)$ & 1.66666 & 2.50000 & 100.0000 & 34.2465 & 44.5407 & 100 \\
\hline
\end{tabular}

to $\mathrm{BD}$ as shown in Table 6 . The table shows that the optimal kernel parameter for swell and sag is $\beta=0.05$ while for interruption, harmonic, interharmonic, and transient signals is $\beta=1.0$. For instance, Figure 7 shows the performance of swell signal using various $\beta$ and its optimal value is identified at $\beta=0.05$.

\section{Adaptive Optimal Kernel}

In the previous section, the performance of SWWVD, CWD, $\mathrm{BD}$, and $\mathrm{MBD}$ is analyzed with various kernel parameters. From the analysis, the optimal performance of the distributions is identified and compared as shown in Table 7. 


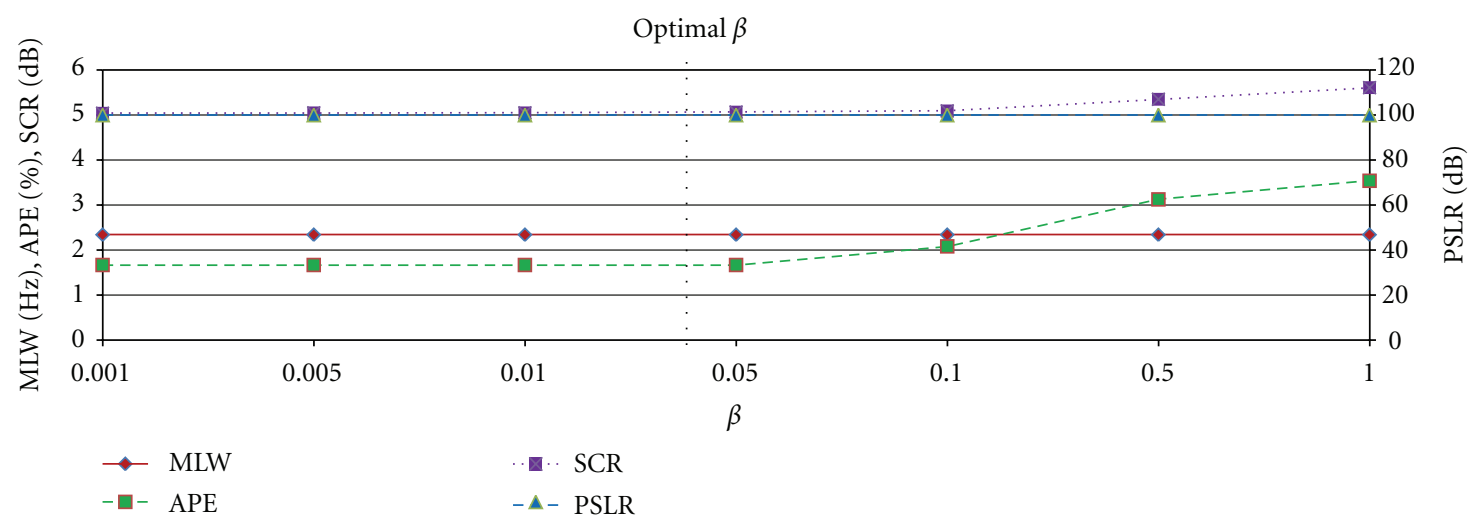

FIGURE 7: Performance comparison of the TFR using MBD with various $\beta$ for swell signal.

TABLe 7: Performance comparison between optimal kernel parameters for the TFDs.

\begin{tabular}{|c|c|c|c|c|c|c|}
\hline Signal & & & SWWVD & CWD & $\mathrm{BD}$ & MBD \\
\hline \multirow{15}{*}{$\begin{array}{l}\text { Voltage } \\
\text { variation signal }\end{array}$} & \multirow{4}{*}{ Swell } & $\operatorname{MLW}(\mathrm{Hz})$ & 25 & 2.34375 & 2.34375 & 2.34375 \\
\hline & & PSLR (dB) & 614.815 & 52.0779 & 100 & 100 \\
\hline & & $\mathrm{SCR}(\mathrm{dB})$ & 15.6408 & 6.53223 & 5.04217 & 5.0679 \\
\hline & & $\mathrm{APE}(\%)$ & 0.20833 & 0.20833 & 1.66666 & 1.66666 \\
\hline & Kernel parameter & & $\begin{array}{l}T_{g}=10 \mathrm{~ms} \\
\mathrm{~T}_{\mathrm{sm}}=0 \mathrm{~ms}\end{array}$ & $\sigma=0.05$ & $\beta=0.001$ & $\beta=0.05$ \\
\hline & \multirow{4}{*}{ Sag } & $\operatorname{MLW}(\mathrm{Hz})$ & 25 & 2.34375 & 2.34375 & 2.34375 \\
\hline & & $\operatorname{PSLR}(\mathrm{dB})$ & 614.815 & 52.0779 & 100 & 100 \\
\hline & & SCR $(\mathrm{dB})$ & 17.7996 & 8.73298 & 7.15816 & 7.19925 \\
\hline & & $\mathrm{APE}(\%)$ & 0.625 & 0.20833 & 2.50000 & 2.50000 \\
\hline & Kernel parameter & & $\begin{array}{l}T_{g}=10 \mathrm{~ms} \\
T_{\mathrm{sm}}=\mathbf{0 ~} \mathrm{ms}\end{array}$ & $\sigma=0.05$ & $\beta=0.001$ & $\beta=0.05$ \\
\hline & \multirow{4}{*}{ Interruption } & $\operatorname{MLW}(\mathrm{Hz})$ & 25 & 2.34375 & 2.34375 & 2.34375 \\
\hline & & $\operatorname{PSLR}(\mathrm{dB})$ & 614.815 & 52.0779 & 100 & 100 \\
\hline & & $\mathrm{SCR}(\mathrm{dB})$ & 55.4463 & 27.4525 & 26.2188 & 29.1182 \\
\hline & & $\mathrm{APE}(\%)$ & 0.625 & 56.8750 & 100.000 & 91.458 \\
\hline & Kernel parameter & & $\begin{array}{l}T_{g}=10 \mathrm{~ms} \\
T_{\mathrm{sm}}=\mathbf{0 ~} \mathrm{ms}\end{array}$ & $\sigma=0.05$ & $\beta=0.001$ & $\beta=1.0$ \\
\hline \multirow{10}{*}{$\begin{array}{l}\text { Waveform } \\
\text { distortion signal }\end{array}$} & \multirow{4}{*}{ Harmonic } & $\operatorname{MLW}(\mathrm{Hz})$ & 6.25 & 9.375 & 2.34375 & 2.34375 \\
\hline & & $\operatorname{PSLR}(\mathrm{dB})$ & 664.295 & 60.5077 & 55.0188 & 45.1706 \\
\hline & & SCR $(\mathrm{dB})$ & 41.7393 & 29.0768 & 23.2079 & 18.3383 \\
\hline & & $\mathrm{APE}(\%)$ & 0.125 & 2.36060 & 10.5308 & 12.7766 \\
\hline & Kernel parameter & & $\begin{aligned} T_{g} & =20 \mathrm{~ms} \\
T_{\mathrm{sm}} & =7.5 \mathrm{~ms}\end{aligned}$ & $\sigma=0.001$ & $\beta=0.05$ & $\beta=1.0$ \\
\hline & \multirow{4}{*}{ Interharmonic } & $\operatorname{MLW}(\mathrm{Hz})$ & 6.25 & 9.375 & 2.34375 & 2.34375 \\
\hline & & $\operatorname{PSLR}(\mathrm{dB})$ & 655.776 & 56.1806 & 55 & 48.2892 \\
\hline & & $\mathrm{SCR}(\mathrm{dB})$ & 42.256 & 30.1635 & 24.1038 & 19.6895 \\
\hline & & $\mathrm{APE}(\%)$ & 0.125 & 25.5125 & 10.1349 & 10.3902 \\
\hline & Kernel parameter & & $\begin{aligned} T_{g} & =20 \mathrm{~ms} \\
T_{\mathrm{sm}} & =6.67 \mathrm{~ms}\end{aligned}$ & $\sigma=0.001$ & $\beta=0.05$ & $\beta=1.0$ \\
\hline \multirow{5}{*}{$\begin{array}{l}\text { Transient } \\
\text { signal }\end{array}$} & \multirow{4}{*}{ Transient } & $\operatorname{MLW}(\mathrm{Hz})$ & 25 & 2.34375 & 2.34375 & 2.34375 \\
\hline & & $\operatorname{PSLR}(\mathrm{dB})$ & 86.1447 & 67.5132 & 56.1906 & 56.1906 \\
\hline & & $\mathrm{SCR}(\mathrm{dB})$ & 14.1705 & 7.0376 & 6.8444 & 6.8444 \\
\hline & & $\mathrm{APE}(\%)$ & 1.66667 & 21.6667 & 2.77778 & 2.77778 \\
\hline & Kernel parameter & & $\begin{aligned} \mathrm{T}_{\mathrm{g}} & =10 \mathrm{~ms} \\
\mathrm{~T}_{\mathrm{sm}} & =1.58 \mathrm{~ms}\end{aligned}$ & $\sigma=1.0$ & $\beta=0.05$ & $\beta=1.0$ \\
\hline
\end{tabular}


The result shows that the SWWVD is the best distribution for power quality signal analysis and an adaptive optimal kernel for SWWVD is designed.

Based on the analysis in Sections 5 and 6, a guideline to determine the separable kernel parameters of SWWVD for power quality signals is given as follows.

(i) For voltage variation signal

$$
T_{g}=10 \mathrm{~ms}, \quad T_{\mathrm{sm}}=0 \mathrm{~ms} .
$$

(ii) For waveform distortion signal

$$
T_{g}=20 \mathrm{~ms}, \quad T_{\mathrm{sm}}=\frac{3}{2\left|f_{2}-f_{1}\right|} .
$$

(iii) For transient

$$
T_{g}=10 \mathrm{~ms}, \quad T_{\mathrm{sm}}=\frac{3}{2\left|f_{2}-f_{1}\right|} .
$$

The kernel parameters are different based on the characteristics of the signals. Hence, an adaptive kernel system is required which is capable of setting the kernel parameters automatically from input signal. In this paper, based on the kernels setting given above, the adaptive kernel system for power quality signal is designed as shown in Figure 8.

Firstly, bilinear product at $\tau=0$ for the input signal is calculated. It can also be called instantaneous energy of the interest signal, $x(t)$ [14], and can be expressed as

$$
K_{x}(t, 0)=x(t) x^{*}(t) .
$$

For the signal models in (1) to (3), the bilinear product at $\tau=0$ of the voltage variation, waveform distortion, and transient signal are, respectively, defined as

$$
\begin{aligned}
K_{z, \mathrm{wv}}(t, 0)= & \sum_{k=1}^{3} A_{k}^{2} \Pi_{k}\left(t-t_{k}\right), \\
K_{z, \mathrm{wd}}(t, 0)= & 1+A^{2}+2 A \cos \left(2 \pi\left(f_{2}-f_{1}\right) t\right), \\
K_{z, \text { trans }}(t, 0)= & \sum_{k=1}^{3} \Pi_{k}\left(t-t_{k}\right) \\
& +\left(A^{2} e^{-2.5\left(t-t_{1}\right)}+2 A e^{-1.25\left(t+\tau / 2-t_{1}\right)}\right. \\
& \left.\quad \times \cos \left(j 2 \pi\left(f_{2}-f_{1}\right) t-f_{2} t_{1}\right)\right) \Pi_{2}\left(t-t_{2}\right) .
\end{aligned}
$$

The above equations show that the voltage variation and transient signal have a momentary energy variation between $t_{1}$ and $t_{2}$, while the waveform distortion has no momentary energy variation. Thus, based on this observation and the guideline given in (36) to (38), the lag window width is set at $T_{g}=10 \mathrm{~ms}$ for the signal that has momentary energy variation, while, for no momentary energy variation, $T_{g}$ is set at $20 \mathrm{~ms}$.

In process to estimate TS function parameters, $T_{\mathrm{sm}}$, ambiguity function of the bilinear at $\tau=0$ is employed.

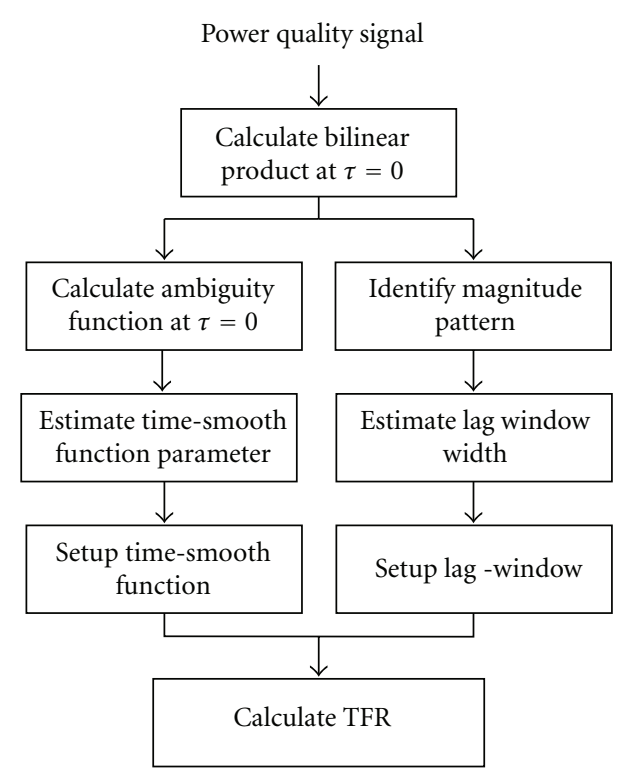

FIgURE 8: Process flow of the adaptive optimal SWWVD.

It is calculated by using (41) to present the Doppler frequency component of the bilinear product. From the ambiguity function, the lowest Doppler frequency, $v_{\min }$, is identified and used to calculate $T_{\mathrm{sm}}$ as defined in (42):

$$
\begin{gathered}
A_{z}(v, 0)=\int_{-\infty}^{\infty} K_{z}(t, 0) e^{-j 2 \pi v t} d t, \\
T_{\mathrm{sm}}=\left[\frac{3}{2 v_{\min }}\right] .
\end{gathered}
$$

As indicated in (40), the waveform distortion and transient signal have a Doppler frequency component at $v=\mid f_{2}-$ $f_{1} \mid$ while the voltage variation has zero Doppler frequency. Thus, for waveform distortion and transient signal, $v_{\min }$ is set at $\left|f_{2}-f_{1}\right|$ and is then used in (42) to calculate $T_{\mathrm{sm}}$. Since the voltage variation has no Doppler frequency, the time-smooth function parameter is set at $T_{\mathrm{sm}}=0 \mathrm{~ms}$, or, in other words, the TS function used is a delta function. For normal signal, it has zero Doppler frequency as well as no energy variation. Therefore, the kernel parameters used are similar to the voltage variation signal which are $T_{g}=10 \mathrm{~ms}$ and $T_{\mathrm{sm}}=0 \mathrm{~ms}$. Finally, the setting of the kernels is used to calculate the SWWVD to represent the signal in TFR.

For example, Figures 9 to 11 show swell, harmonic, and transient signals and their bilinear product and ambiguity function at $\tau=0$, respectively. As shown in Figure 9(a), the magnitude of the swell signal is 1.2 pu starting from 100 to $140 \mathrm{~ms}$, while Figure 9(b) shows that its energy increases from 1 to $1.44 \mathrm{pu}$ between 100 and $140 \mathrm{~ms}$. The signal has zero Doppler-frequency as shown in Figure 9(c). For harmonic signal in Figure 10(a), it is a constant sinusoidal energy as shown in Figure 10(b), while Figure 10(c) shows its Doppler frequency is $v=200 \mathrm{~Hz}$. It is different from the transient signal that has a short energy variation between 100 and $115 \mathrm{~ms}$, while its Doppler frequency is at $v=950 \mathrm{~Hz}$ as shown in Figures 11(b) and 11(c), respectively. 


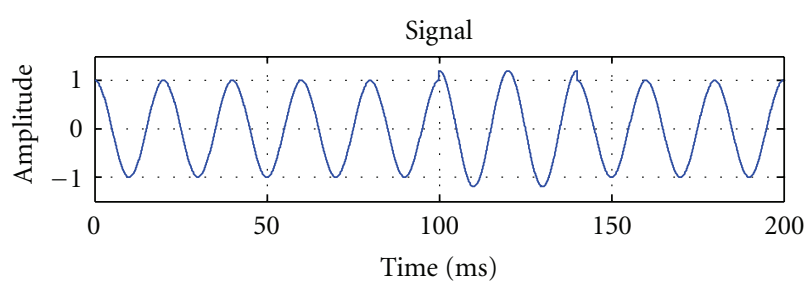

(a)

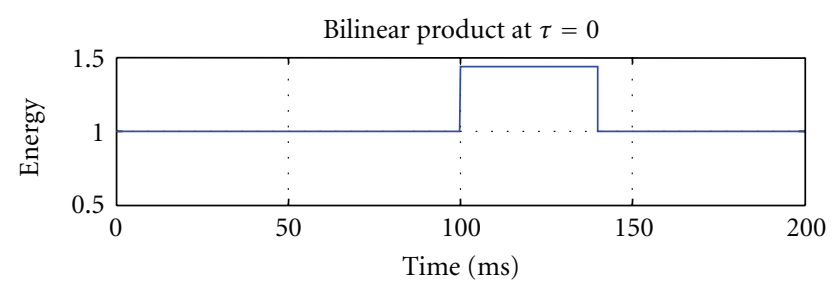

(b)

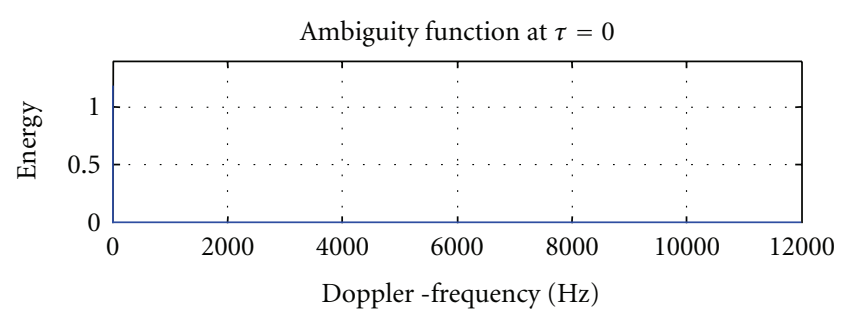

(c)

Figure 9: (a) Swell signal, (b) its bilinear product, and (c) ambiguity function at $\tau=0$.

Based on the adaptive system design, since the bilinear product at $\tau=0$ of swell and transient signals has a momentary energy variation, the lag window width is set at $T_{g}=10 \mathrm{~ms}$. For harmonic signal that has no momentary energy variation, the lag window width is set at $T_{g}=$ $20 \mathrm{~ms}$. The harmonic and transient signals have a Doppler frequency. Thus, the values of the Doppler frequency are used in (42) to calculate $T_{\mathrm{sm}}$. As a result, the setting of $T_{\mathrm{sm}}$ for the harmonic and transient signals is 7.5 and $1.578 \mathrm{~ms}$, respectively. For the swell signal, it has no Doppler frequency component, and $T_{\mathrm{sm}}$ is set at $0 \mathrm{~ms}$.

\section{Results}

In this section, the results of the power quality analysis using SWWVD, CWD, BD, and MBD are discussed. The example of the signals and their TFRs using the TFDs at optimal kernels is shown in Figures 12 to 15. The line graphs show the signal in time domain, while the contour plots show the TFR. The highest power is represented in red color while the lowest in blue color.

Figure 12 shows a sag signal and its TFR using SWWVD. The magnitude of the sag signal is $0.8 \mathrm{pu}$, while its duration is between 100 and $140 \mathrm{~ms}$. The contour plot presents that there is a momentary decrease of power at $50 \mathrm{~Hz}$ (fundamental frequency) from 100 to $140 \mathrm{~ms}$. In Figure 13, there is a harmonic signal in time domain and its TFR

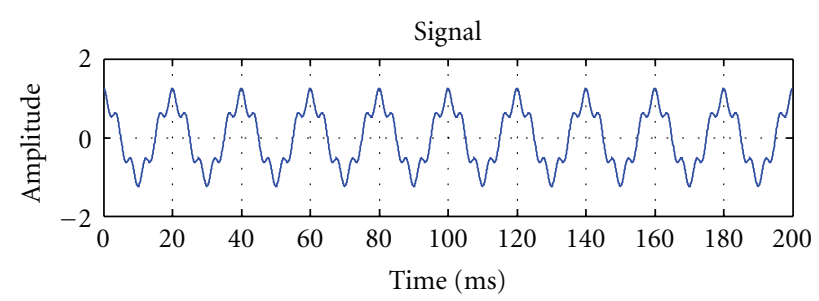

(a)

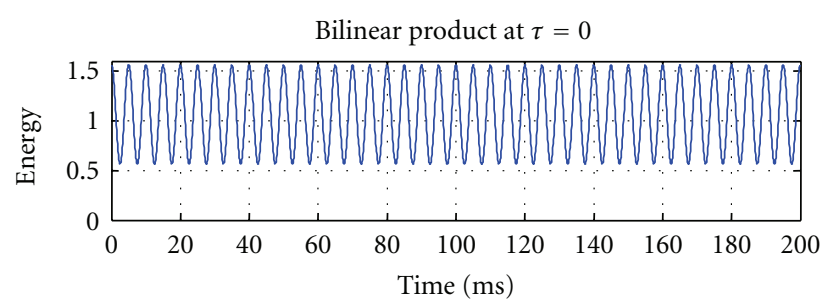

(b)

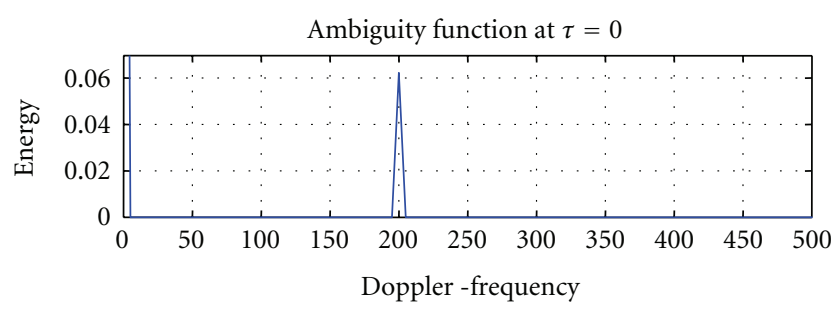

(c)

FIGURE 10: (a) Harmonic signal, (b) its bilinear product, and (c) ambiguity function at $\tau=0$.

by using CWD. The TFR shows that the harmonic signal consists of two frequency components which are 50 and $250 \mathrm{~Hz}$.

A swell signal and its TFR using BD are shown in Figure 14. The magnitude of the swell signal is $1.2 \mathrm{pu}$ between 100 and $140 \mathrm{~ms}$. The TFR shows that the power increases from 120 to $160 \mathrm{~ms}$, and its frequency is $50 \mathrm{~Hz}$. The last example is transient signal. This signal and its TFR using MBD are shown in Figure 15. The transient signal begins at $100 \mathrm{~ms}$, and its duration is $15 \mathrm{~ms}$. In the contour plot, the transient power increases between 118 and $125 \mathrm{~ms}$, and its frequency is $1000 \mathrm{~Hz}$.

In the contour plots, the TFRs show some delays compared to the input signals. This is because the convolution process between kernel and signal in the TFDs shifts the TFRs in time domain. For the TFR of sag signal using SWWVD, there is no delay because the kernel parameter used for time-smooth function is set at $T_{\mathrm{sm}}=0 \mathrm{~ms}$. Generally, this observation clearly shows that the TFRs represent the characteristics of the power quality signals.

By assuming perfect knowledge of the power quality signals, the performance of the bilinear TFDs with various kernel parameters has been analyzed as shown in Tables 3 to 6 . From those tables, the optimal performance of the TFDs is identified and summarized in Table 7.

A good TFD should have low APE and MLW while high SCR and PSLR. This table shows that, in overall, SWWVD 


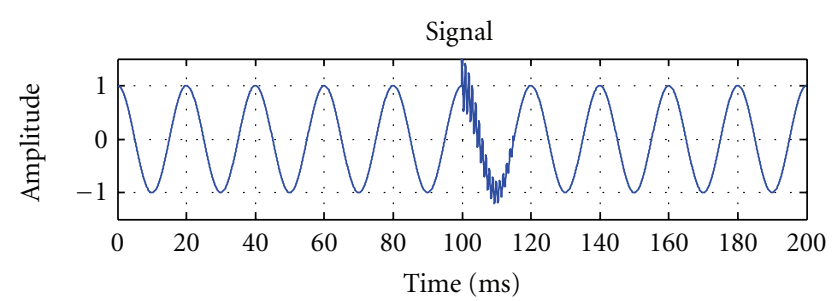

(a)

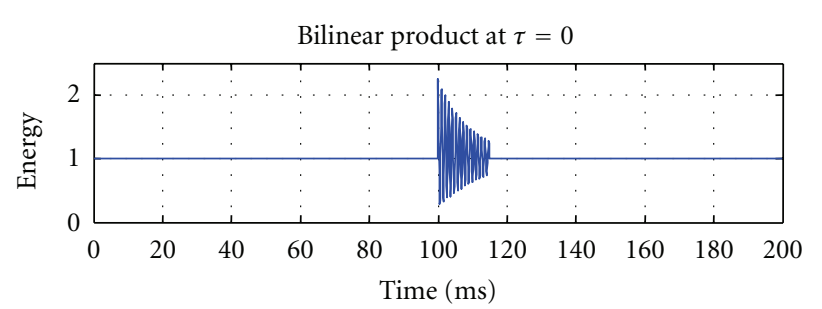

(b)

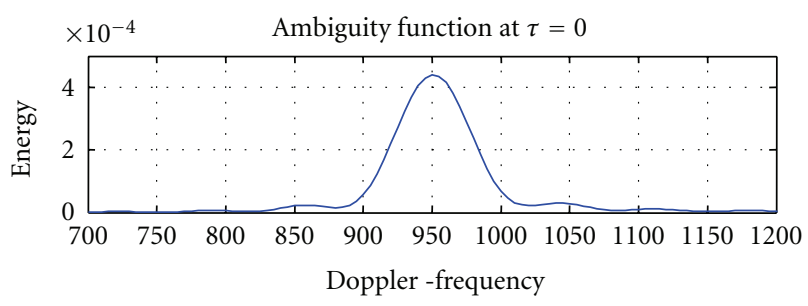

(c)

FIGURE 11: (a) Harmonic signal, (b) its bilinear product, and (c) ambiguity function at $\tau=0$.
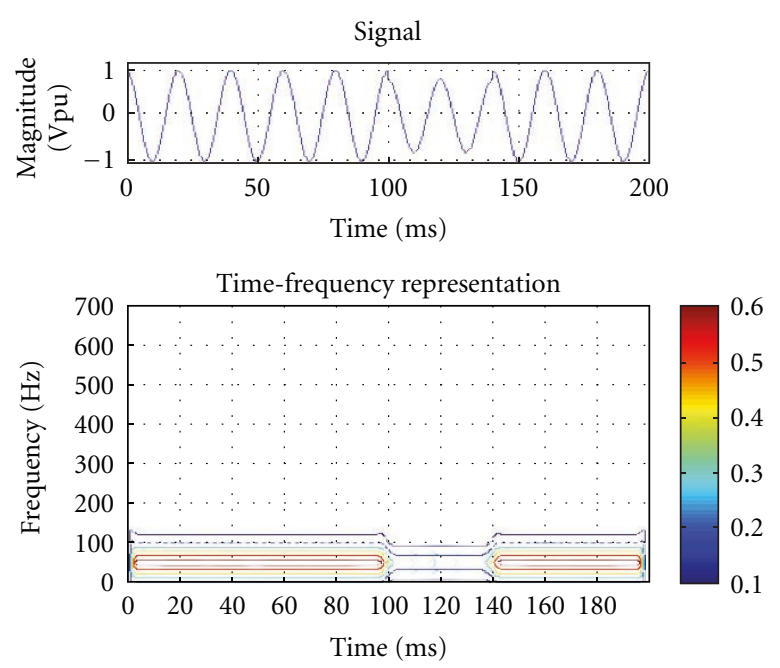

FIGURE 12: The TFR of sag signal using SWWVD at $T_{g}=10 \mathrm{~ms}$ and $T_{\text {sm }}=0 \mathrm{~ms}$.

gives good APE, SCR, and PSLR while MLW is poor. For CWD, BD, and MBD, they offer good MLW but poor APE, SCR, and PSLR. Thus, it clearly proves that the SWWVD is the best distribution and very appropriate for power quality analysis.
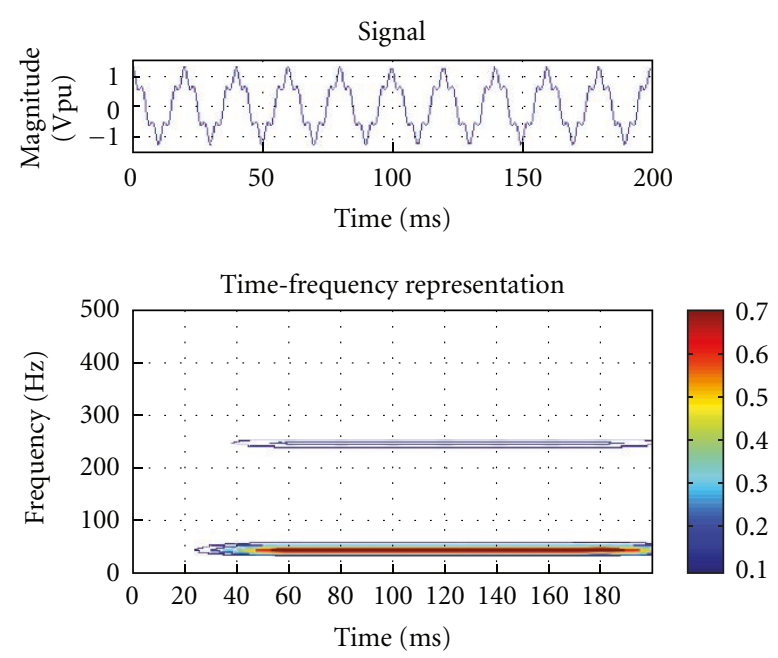

FIGURE 13: The TFR of harmonic signal using CWD at $\sigma=0.001$.
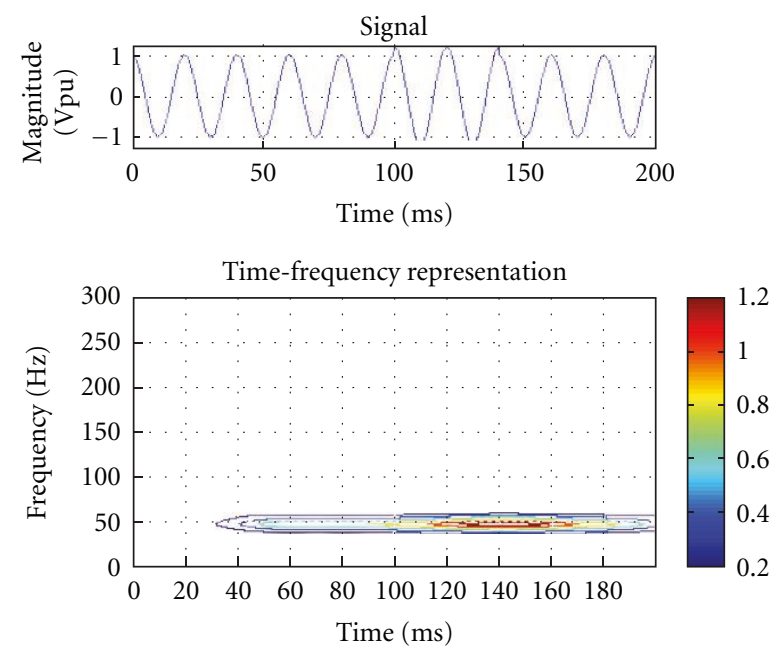

FIgURE 14: The TFR of swell signal using BD at $\beta=0.001$.
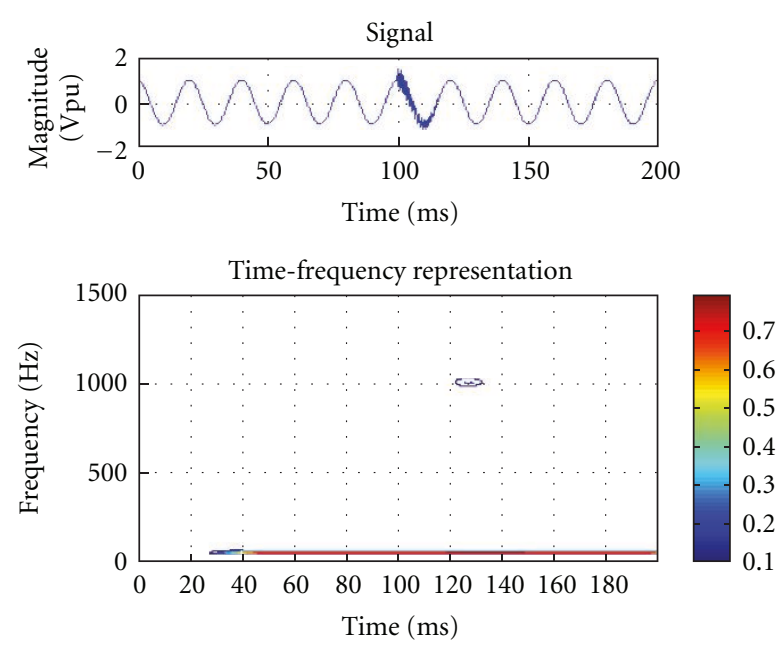

FIgURE 15: The TFR of transient signal using MBD at $\beta=1.0$. 
TABLE 8: Performance comparison between optimal and adaptive optimal kernel parameters.

\begin{tabular}{|c|c|c|c|c|}
\hline Signal & & $\begin{array}{c}\text { Performance } \\
\text { measures }\end{array}$ & Optimal & Adaptive \\
\hline \multirow{14}{*}{$\begin{array}{l}\text { Voltage } \\
\text { variation } \\
\text { signal }\end{array}$} & \multirow{4}{*}{ Swell } & MLW $(\mathrm{Hz})$ & 25 & 25 \\
\hline & & PSLR (dB) & 614.815 & 614.815 \\
\hline & & SCR (dB) & 15.6408 & 15.6408 \\
\hline & & APE (\%) & 0.20833 & 0.20833 \\
\hline & \multirow{4}{*}{ Sag } & MLW $(\mathrm{Hz})$ & 25 & 25 \\
\hline & & PSLR (dB) & 614.815 & 614.815 \\
\hline & & SCR (dB) & 17.7996 & 17.7996 \\
\hline & & $\mathrm{APE}(\%)$ & 0.625 & 0.625 \\
\hline & \multirow{4}{*}{ Interruption } & MLW $(\mathrm{Hz})$ & 25 & 25 \\
\hline & & $\operatorname{PSLR}(\mathrm{dB})$ & 614.815 & 614.815 \\
\hline & & SCR (dB) & 55.4463 & 55.4463 \\
\hline & & APE (\%) & 0.625 & 0.625 \\
\hline & Kernel & $T_{g}(\mathrm{~ms})$ & 10 & 10 \\
\hline & parameter & $T_{\mathrm{sm}}^{\circ}(\mathrm{ms})$ & 0 & 0 \\
\hline \multirow{12}{*}{$\begin{array}{l}\text { Waveform } \\
\text { distortion } \\
\text { signal }\end{array}$} & \multirow{4}{*}{ Harmonic } & MLW $(\mathrm{Hz})$ & 6.25 & 6.25 \\
\hline & & PSLR (dB) & 664.295 & 664.295 \\
\hline & & $\mathrm{SCR}(\mathrm{dB})$ & 41.7393 & 41.7393 \\
\hline & & APE (\%) & 0.125 & 0.125 \\
\hline & \multirow{3}{*}{$\begin{array}{c}\text { Kernel } \\
\text { parameter }\end{array}$} & $T_{g}(\mathrm{~ms})$ & 20 & 20 \\
\hline & & $T_{s \mathrm{~m}}(\mathrm{~ms})$ & 7.5 & 7.5 \\
\hline & & MLW $(\mathrm{Hz})$ & 6.25 & 6.25 \\
\hline & \multirow{3}{*}{ Interharmonic } & PSLR (dB) & 655.776 & 655.776 \\
\hline & & $\mathrm{SCR}(\mathrm{dB})$ & 42.256 & 42.256 \\
\hline & & APE (\%) & 0.125 & 0.125 \\
\hline & Kernel & $T_{g}(\mathrm{~ms})$ & 20 & 20 \\
\hline & parameter & $T_{\mathrm{sm}}(\mathrm{ms})$ & 6.67 & 6.67 \\
\hline \multirow{6}{*}{$\begin{array}{l}\text { Transient } \\
\text { signal }\end{array}$} & \multirow{4}{*}{ Transient } & MLW $(\mathrm{Hz})$ & 25 & 25 \\
\hline & & $\operatorname{PSLR}(\mathrm{dB})$ & 86.1447 & 86.1447 \\
\hline & & SCR $(\mathrm{dB})$ & 14.1705 & 14.1705 \\
\hline & & APE (\%) & 1.66667 & 1.66667 \\
\hline & Kernel & $T_{g}(\mathrm{~ms})$ & 10 & 10 \\
\hline & parameter & $T_{\mathrm{sm}}^{\circ}(\mathrm{ms})$ & 1.578 & 1.578 \\
\hline
\end{tabular}

For any unknown signal, an adaptive optimal kernel SWWVD system is designed as discussed in Section 7 to determine automatically the optimal kernel parameters. Then, the performance of the adaptive kernel is identified and compared with the performance of the optimal kernel as shown in Table 8.

This table shows that, for every signal, the adaptive kernel gives similar parameters to the optimal kernel. As a result, the performance of adaptive kernel is comparable to the performance of optimal kernel. In addition, the adaptive system also gives high accuracy for the measurement of the signal characteristics as discussed in Section 6.1. Therefore, the adaptive kernel system is suitable to be implemented for power quality analysis as well as for classification purpose.

The performance of SWWVD for power quality signals classification in noisy condition has been discussed in [15]. A set of 100 signals with various characteristics for each type of power quality signal were generated and classified at SNR from 0 to $40 \mathrm{~dB}$. The results show that the system can classify all signals without error at $36 \mathrm{~dB}$ of SNR and above.

\section{Conclusions}

This paper presents the analysis of power quality signals using SWWVD, CWD, BD, and MBD to identify the optimal kernel parameters. The performance measures used are MLW, PSLR, SCR, and APE. The results show that different power quality signals need different kernel parameters for optimal TFR. There is no one kernel parameter that can be used optimally for all signals.

At the optimal kernel setting, the SWWVD gives the best performance of TFR compared to the other TFDs, and its adaptive optimal kernel is designed. The adaptive system can obtain optimal kernel setting automatically without prior knowledge of the signal. The result shows that the adaptive kernels system is comparable to the optimal kernel and is suitable for power quality analysis and classification purpose.

\section{Appendices}

The bilinear product that is given in (6) represents a signal in time-lag representation. This representation consists of two terms: autoterms and cross-terms as defined in (16). This section discusses the calculation of bilinear product to obtain the autoterms and cross-terms for the power quality signals.

\section{A. The Voltage Variation Signal}

The voltage variation signal in (1) has three sequence signals at fundamental frequency, $f_{1}$, and its bilinear product is given as

$$
\begin{aligned}
& K_{z, \mathrm{vv}}(t, \tau)=\left(e^{j 2 \pi f_{1}(t+\tau / 2)} \sum_{k=1}^{3} A_{k} \Pi_{k}\left(t+\frac{\tau}{2}-t_{k-1}\right)\right) \\
& \times\left(e^{-j 2 \pi f_{1}(t-\tau / 2)} \sum_{l=1}^{3} A_{l} \Pi_{l}\left(t-\frac{\tau}{2}-t_{l-1}\right)\right) \\
&= e^{j 2 \pi f_{1} \tau} \sum_{k=1}^{3} \sum_{l=1}^{3} A_{k} A_{l} \Pi_{k}\left(t+\frac{\tau}{2}-t_{k-1}\right) \\
& \times \Pi_{l}\left(t-\frac{\tau}{2}-t_{l-1}\right),
\end{aligned}
$$

where $A_{k}$ and $A_{l}$ are the signal amplitude, $t_{k}$ and $t_{l}$ are the time, $k$ and $l$ are the signal sequence starting with one, and $\Pi(t)$ is a box function of the signal as expressed in (4). 
The autoterms are bilinear product of a signal with the same signal, $k=l$. Thus, the autoterms for this signal are defined as

$$
\begin{gathered}
K_{\text {auto,vv }}(t, \tau)=e^{j 2 \pi f_{1} \tau} \sum_{k=1}^{3}\left|A_{k}\right|^{2} \Pi_{k}\left(t+\frac{\tau}{2}-t_{k-1}\right) \\
\times \Pi_{k}\left(t-\frac{\tau}{2}-t_{k-1}\right) \\
=e^{j 2 \pi f_{1} \tau} \sum_{k=1}^{3}\left|A_{k}\right|^{2} K_{\Pi_{k, k}}(t, \tau), \\
K_{\Pi_{k, l}}(t, \tau)=\Pi_{k}\left(t+\frac{\tau}{2}-t_{k-1}\right) \Pi_{l}\left(t-\frac{\tau}{2}-t_{k-1}\right) .
\end{gathered}
$$

The cross-terms are bilinear product between different signal, $k \neq l$, and expressed as

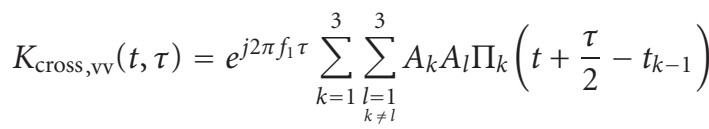

$$
\begin{aligned}
& \times \Pi_{l}\left(t-\frac{\tau}{2}-t_{l-1}\right) \\
& =e^{j 2 \pi f_{1} \tau} \sum_{k=1}^{3} \sum_{\substack{l=1 \\
k \neq l}}^{3} A_{k} A_{l} K_{\Pi_{k, l}}(t, \tau) .
\end{aligned}
$$

\section{B. The Waveform Distortion Signal}

The waveform distortion signal in (2) is different from the previous signal that has one signal and consists of two frequency components, $f_{1}$ and $f_{2}$. Its bilinear product is expressed as

$$
\begin{aligned}
K_{z, \mathrm{wd}}(t, \tau)= & \left(e^{j 2 \pi f_{1}(t+\tau / 2)}+A e^{j 2 \pi f_{2}(t+\tau / 2)}\right) \\
& \times\left(e^{-j 2 \pi f_{1}(t-\tau / 2)}+A e^{-j 2 \pi f_{2}(t-\tau / 2)}\right) \\
= & e^{j 2 \pi f_{1} \tau}+A^{2} e^{j 2 \pi f_{2} \tau}+2 A e^{j 2 \pi\left(\left(f_{2}+f_{1}\right) / 2\right) \tau} \\
& \times \cos \left(2 \pi\left(f_{2}-f_{1}\right) t\right) .
\end{aligned}
$$

The function above shows that the autoterms have two lagfrequency components similar to the signal frequencies, $f_{1}$ and $f_{2}$ frequencies, while the cross-terms exist in the middle between the lag-frequency components, $\left(f_{2}+f_{1}\right) / 2$, and have a Doppler frequency at $v=f_{2}-f_{1}$. The autoterms and crossterms are defined as

$$
\begin{gathered}
K_{\text {auto }, z \mathrm{wd}}(t, \tau)=e^{j 2 \pi f_{1} \tau}+A^{2} e^{j 2 \pi f_{2} \tau}, \\
K_{\text {cross }, z \mathrm{wd}}(t, \tau)=2 A e^{j 2 \pi\left(\left(f_{2}+f_{1}\right) / 2\right) \tau} \cos \left(2 \pi\left(f_{2}-f_{1}\right) t\right) .
\end{gathered}
$$

\section{The Transient Signal}

The transient signal in (3) has three sequence signals. The first and third signals are normal signal at fundamental frequency, $f_{1}$, while the second signal has additional transient frequency, $f_{2}$. The bilinear product of this signal is defined as

$$
\begin{aligned}
& K_{z, \text { trans }}(t, \tau)=\left(e^{j 2 \pi f_{1}(t+\tau / 2)} \sum_{k=1}^{3} \Pi_{k}\left(t+\frac{\tau}{2}-t_{k-1}\right)\right. \\
& +A e^{-1.25\left(t+\tau / 2-t_{1}\right) / t_{d}} e^{j 2 \pi f_{2}\left(t+\tau / 2-t_{1}\right)} \\
& \left.\times \Pi_{2}\left(t+\frac{\tau}{2}-t_{1}\right)\right) \\
& \times\left(e^{-j 2 \pi f_{1}(t-\tau / 2)} \sum_{l=1}^{3} \Pi_{l}\left(t-\frac{\tau}{2}-t_{k-1}\right)\right. \\
& +A e^{-1.25\left(t-\tau / 2-t_{1}\right) / t_{d}} e^{-j 2 \pi f_{2}\left(t-\tau / 2-t_{1}\right)} \\
& \left.\times \Pi_{2}\left(t-\frac{\tau}{2}-t_{1}\right)\right) \\
& =A^{2} e^{-2.5\left(t-t_{1}\right)} e^{j 2 \pi f_{2} \tau} K_{\Pi_{2,2}}(t, \tau) \\
& +\sum_{k=1}^{3} \sum_{l=1}^{3} e^{j 2 \pi f_{1} \tau} K_{\Pi_{k, l}}(t, \tau) \\
& +\sum_{l=1}^{3} A e^{-1.25\left(t+\tau / 2-t_{1}\right)} e^{-j 2 \pi\left(f_{2}-f_{1}\right) t-f_{2} t_{1}} \\
& \times e^{j 2 \pi\left(f_{2}+f_{1}\right) \tau / 2} K_{\Pi_{2, l}}(t, \tau) \\
& +\sum_{k=1}^{3} A e^{-1.25\left(t+\tau / 2-t_{1}\right)} e^{-j 2 \pi\left(f_{2}-f_{1}\right) t-f_{2} t_{1}} \\
& \times e^{j 2 \pi\left(f_{2}+f_{1}\right) \tau / 2} K_{\Pi_{k, 2}}(t, \tau) .
\end{aligned}
$$

As discussed for the voltage variation and waveform distortion signal, autoterms and cross-terms of transient signal can be defined as

$$
\begin{aligned}
K_{\text {auto,trans }}(t, \tau)= & \sum_{k=1}^{3} e^{j 2 \pi f_{1} \tau} K_{\Pi_{k, k}}(t, \tau)+A^{2} e^{-2.5\left(t-t_{1}\right)} e^{j 2 \pi f_{2} \tau} \\
& \times K_{\Pi_{2,2}}(t, \tau), \\
K_{\text {trans,cross }}(t, \tau)= & \sum_{k=1}^{3} \sum_{l=1}^{3} e^{j 2 \pi f_{1} \tau} K_{\Pi_{k, l}}(t, \tau) \\
+ & \sum_{l=1}^{3} A e^{-1.25\left(t+\tau / 2-t_{1}\right)} e^{j 2 \pi\left(f_{2}-f_{1}\right) t-f_{2} t_{1}} \\
& \times e^{j 2 \pi\left(f_{2}+f_{1}\right) \tau / 2} K_{\Pi_{2, l}}(t, \tau) \\
+ & \sum_{k=1}^{3} A e^{-1.25\left(t+\tau / 2-t_{1}\right)} e^{-j 2 \pi\left(f_{2}-f_{1}\right) t-f_{2} t_{1}} \\
& \times e^{j 2 \pi\left(f_{2}+f_{1}\right) \tau / 2} K_{\prod_{k, 2}}(t, \tau) .
\end{aligned}
$$




\section{Acknowledgments}

The authors would like to thank Technical university of Malaysia Malacca (UTeM) for its financial support and Technical university of Malaysia for providing the resources for this research.

\section{References}

[1] D. B. Vannoy, M. F. McGranaghan, S. M. Halpin, W. A. Moncrief, and D. D. Sabin, "Roadmap for power-quality standards development," IEEE Transactions on Industry Applications, vol. 43, no. 2, pp. 412-421, 2007.

[2] R. B. Godoy, J. O. P. Pinto, and L. Galotto Jr., "Multiple signal processing techniques based power quality disturbance detection, classification, and diagnostic software," in Proceedings of the 9th International Conference on Electrical Power Quality and Utilisation (EPQU'07), pp. 1-6, Barcelona, Spain, October 2007.

[3] K.-K. Poh and P. Marziliano, "Analysis of neonatal EEG signals using stockwell transform," in Proceedings of the IEEE International Conference on Engineering in Medicine and Biology Society (EMBS '07), pp. 594-597, Lyon, France, August 2007.

[4] Z. Shi, L. Ruirui, W. Qun, J. T. Heptol, and Y. Guimin, "The research of power quality analysis based on improved Stransform," in Proceedings of the 9th International Conference on Electronic Measurement and Instruments (ICEMI '09), vol. 2, pp. 2477-2481, Beijing, China, August 2009.

[5] T. Radii, P. M. Ramos, and A. C. Serra, "Detection and extraction of harmonic and non-harmonic power quality disturbances using sine fitting methods," in Proceedings of the 13th International Conference on Harmonics and Quality of Power (ICHQP '08), pp. 1-6, Wollongong, Australia, September 2008.

[6] F. Zhao and R. Yang, "Power-quality disturbance recognition using S-transform," IEEE Transactions on Power Delivery, vol. 22, no. 2, pp. 944-950, 2007.

[7] B. Barkat and B. Boashash, "A high-resolution quadratic timefrequency distribution for multicomponent signals analysis," IEEE Transactions on Signal Processing, vol. 49, no. 10, pp. 2232-2239, 2001.

[8] L. Stanković, "Auto-term representation by the reduced interference distributions: a procedure for kernel design," IEEE Transactions on Signal Processing, vol. 44, no. 6, pp. 1557-1563, 1996.

[9] "IEEE recommended practice for monitoring electrical power quality," IEEE Standards 1159-1995 Approved, June 1995.

[10] B. Boashash, Time-Frequency Signal Analysis and Processing: A Comprehensive Reference, Elsevier, Amsterdam, The Netherlands, 2003.

[11] A. R. Abdullah and A. Z. Sha'ameri, "Power quality analysis using linear time-frequency distribution," in Proceedings of the 2nd IEEE International Power and Energy Conference (PECon '08), pp. 313-317, Johor, Malaysia, December 2008.

[12] J. L. Tan and A. Z. B. Sha'Ameri, "Adaptive optimal kernel smooth-windowed wigner-ville distribution for digital communication signal," EURASIP Journal on Advances in Signal Processing, vol. 2008, Article ID 408341, 2008.

[13] A. Moreno, Power Quality: Mitigation Technologies in a Distributed Environment, Springer, New York, NY, USA, 2007.
[14] Z. Sharif, M. S. Zainal, A. Z. Sha'ameri, and S. H. S. Salleh, "Analysis and classification of heart sounds and murmurs based on the instantaneous energy and frequency estimations," in Proceedings of the IEEE International Conference on Intelligent System and Technologies for the New Millennium (TENCON '00), vol. 2, pp. 130-134, Kuala Lumpur, Malaysia, September 2000.

[15] A. R. Abdullah, A. Z. Sha'ameri, and A. Jidin, "Classification of power quality signals using smooth-windowed WignerVille distribution," in Proceedings of the IEEE International Conference on Electrical Machines and System (ICEMS '10), pp. 1981-1985, Incheon, Korea, October 2010. 